\title{
Microalgae as Future Superfoods: Fostering Adoption through Practice-Based Design Research
}

\author{
Maurizio Vrenna ${ }^{1, *(\mathbb{D}}$, Pier Paolo Peruccio ${ }^{2}{ }^{\mathbb{D}}$, Xin Liu $^{3}$, Fang Zhong ${ }^{3}$ and Yuchi Sun ${ }^{4}$ \\ 1 Michael Graves College of Architecture and Design, Wenzhou-Kean University, Wenzhou 325060, China \\ 2 Department of Architecture and Design, Politecnico di Torino, 10125 Torino, Italy; \\ pierpaolo.peruccio@polito.it \\ 3 Academy of Arts and Design, Tsinghua University, Beijing 100084, China; xinl@tsinghua.edu.cn (X.L.); \\ zhongfang@mail.tsinghua.edu.cn (F.Z.) \\ 4 Independent Researcher, Beijing 100009, China; sunyuchi19930321@163.com \\ * Correspondence: mvrenna@kean.edu
}

Citation: Vrenna, M.; Peruccio, P.P.; Liu, X.; Zhong, F.; Sun, Y. Microalgae as Future Superfoods: Fostering Adoption through Practice-Based Design Research. Sustainability 2021, 13, 2848. https://doi.org/10.3390/ su13052848

Academic Editor: Hossein Azadi

Received: 11 February 2021

Accepted: 1 March 2021

Published: 6 March 2021

Publisher's Note: MDPI stays neutral with regard to jurisdictional claims in published maps and institutional affiliations.

Copyright: (c) 2021 by the authors. Licensee MDPI, Basel, Switzerland. This article is an open access article distributed under the terms and conditions of the Creative Commons Attribution (CC BY) license (https:// creativecommons.org/licenses/by/ $4.0 /)$.

\begin{abstract}
Consumers' eating habits are gradually changing. In the next few decades, this shift will not be solely dictated by individuals' decisions but by the need to feed an ever-increasing population in the face of global resources' impoverishment. Novel superfoods rich in nutrients and produced with sustainable methods, including microalgae, maybe a solution. However, their unusual aspect, the palatability, and the lack of knowledge by most people could be obstacles to adoption. This study aims at encouraging the use of microalgae as food, highlighting the importance that design plays in the transition towards more sustainable production and consumption patterns. Through practice-based design research, characterized by empirical experiments, a survey, an engaging workshop, and the development of a fully-functional open-source product, the authors conceptualize a theoretical framework within which similar product-service systems could thrive. This realworld experimentation is of interest for academics, professionals, makers in the field of design, etc. It suggests that multidisciplinarity, education, and replicability are the keys to addressing this topic and paves the way for further technical and humanistic research.
\end{abstract}

Keywords: microalgae; future superfoods; practice-based design research; product-service systems; open-source

\section{Introduction}

Present generations will be living in a different world characterized by new environmental, social, economic, and geopolitical equilibria. A consequence of this new equilibria may be food will no longer be available in the near future without restrictions, especially since the recent COVID-19 crisis has aggravated the situation: as warned by Oxfam [1], millions of people worldwide are being pushed towards hunger by the pandemic, even in wealthier countries. A radical shift in our eating habits is imperative, and it demands a long-term vision. Targeted interventions and multidisciplinary projects with top-down and bottom-up approaches are required. As home to $20 \%$ of the world population but with only $7 \%$ of the total arable land [2], China faces the pressure of providing adequate protein to the people. Proteins are the key elements of human vitality and come from two types of sources: animal and vegetable. Eastern Asia has developed a vegetable-protein-based diet since more than a thousand years ago. Maintaining a balanced diet would not only contribute to the individual health but also relieve the environmental pressure of adopting a high fat, high protein western style. Nevertheless, when the well-educated and highly-informed young generations obtain the autonomy to decide their everyday meals, old fashioned tofu may not be attractive enough. New foods, which may never have appeared on the dinner table, would be a possible solution. 
This study investigates microalgae as a possible nutritional alternative by mainly addressing the Sustainable Development Goals [3] nos. 2 (Zero hunger) and 12 (Responsible consumption and production). In recent years, the discipline of design has become even more inclusive and attentive to environmental issues: this study indeed highlights the fundamental role that design research and the self-production of open-source devices play in the transition towards sustainable consumption patterns. Particularly, this research's objectives are advancing knowledge in the field of phycology to apply it in sustainable design, identifying new fields of environmental-friendly action, experimenting with the design of new open-source technical solutions, and decentralizing microalgae production for food use.

\section{Background}

"It took almost 10,000 years for food grain production to reach 1 billion tons, in 1960, and only 40 years to reach 2 billion tons, in 2000. This unprecedented increase [ ... ] has been named the "green revolution'" [4] (p. 815). The green revolution testified to a spectacular increase in food production. The revolution has been possible because of the use of new technologies, disruptive agronomic practices, the creation of geneticallyimproved crop varieties, and the extensive use of fertilizers and pesticides. This 'miracle' rapidly met a growing population's needs, especially in some of the most impoverished areas of the planet. However, "it is unclear whether high-intensity agriculture can be sustained, because of the loss of soil fertility, the erosion of soil, the increased incidence of crop and livestock diseases, and the high energy and chemical inputs associated with it" [5] (p. 211), and a new green revolution is needed now more than ever. "Population growth, ongoing soil degradation and increasing costs of chemical fertilizer will make the second Green Revolution a priority [ . . ] in the 21st century" [6] (p. 493). The new green revolution will feature a fresh approach to problems. It will focus on chemical and technological improvements, but also on supply chains and behavior change, acting on a few points: avoid deforestation as a priority; increase current yields through organic, high-tech, and precision farming systems; use resources efficiently and differently; change diets, especially in wealthier countries; reduce food waste [7].

Governments, private research institutes, and venture capitalists are investing in the research and development of healthy, tasty, and low environmental impact novel foods. These novel foods are a fascinating field to explore. The discipline of designwhich today is no longer exclusively linked to the design of products but takes on an increasingly important role in redefining services, systems, and problem-solving strategiescan empower us to think of new solutions.

\subsection{Novel Superfoods}

Food futurologists are convinced what we will eat in the coming years will be very different from what we have been used to until now. Novel foods will become part of our diets, replacing — at least partially—some of the most common ingredients. "Novel foods' constitute a food regulatory construct employed in many countries [ ... ] and are referred to as 'new dietary ingredients' in the United States. Novel foods include foods and ingredients that have not been used to any significant extent in a particular country prior to a specific date specified in a food regulation. Novel foods include pure chemicals, genetically modified foods, cloned animals, whole foods new to a particular world region, and foods processed by a new technology" [8] (p. 79).

"There is increasing demand for functional foods [ . . ] with perceived health benefits. This offers promotion opportunities for food manufacturers in a competitive market" [9] (p. 17). With a growing number of people interested in reducing or eliminating meat consumption - for health, nutritional, or ethical reasons - the plant-based meat market is, therefore, booming. Plant-based meat is created to mimic the properties found in natural meat: color, consistency, taste. These products' main ingredients are highly nutritious, i.e., legumes, wheat gluten, and tofu. Plant-based meat is less input-intensive than traditional 
meat and requires minimum water for its production. Consumers believe plant-based meat alternatives promote good health and are environmentally friendly. Moreover, there is a potential for product innovation to ensure adequate attention to micronutrients, especially for vegan and vegetarian consumers [10]. Food supplements and meal replacements (drinks, tablets, soups, etc.) are also particularly appreciated by athletes and healthconscious people who are more attentive to a balanced diet. Startup companies in this sector offer a wide range of meticulously-blended drinks and foods with complete nutritional values [11]. Certain insects are considered a delicacy in some Asian countries, and due to their high protein content, insects may be integrated into more familiar products such as flours and snacks. "Insects represent an edible material of great potential interest for food scientists. [ ... ] Despite the cultural barriers related to their consumption, scientists and policy makers concurred in considering insects as one of the best opportunities to cope with the need of feeding humanity in the future" [12] (p. 11). Several studies are also being conducted on lab-grown meat, an innovative form of cellular agriculture for producing meat in vitro rather than slaughtering animals (this meat price is still high-despite a quick price fall in recent years-and its production raises several ethical issues, interesting especially to vegans) [13]. Consumers are also rediscovering natural ingredients with excellent properties such as algae and microalgae.

Most of the novel foods mentioned above can be considered 'superfoods' because of their unique nutritional profiles. The term superfood is very popular; however, there is no universally recognized legal or scientific definition for it [14]. As a matter of fact, "superfood is a marketing term promoting certain foods that are associated with high concentrations of vitamins, minerals, fibers, essential fatty acids, or antioxidants [ ... ] which '[Westerners] are having a wild love affair with'" [15] (p. 218). Even though the list of superfood-labeled items is long, the most up-and-coming future superfoods are meal replacements, plant-based meat, lab-grown meat, insects, mushrooms, seaweed, and microalgae. For the purposes of this essay, we will consider superfoods to be foods with a high protein content. Table 1 qualitatively compares them and underlines why microalgae are the focus of this research. The parameters taken into account are on a scale of 1-4, where 1 is generally very poor, while 4 is very good.

- Type: synthetic or natural.

- Presence in diets: if the food is already present in today's diets or not and if so, its diffusion.

- Nutritional value: the amount of protein in percentage.

- Acceptance: the degree of acceptability. For example, the appearance of insects could be a barrier to adoption, as well as the atypical color of microalgae.

- Palatability: if the food taste is overall pleasant, or if it may be an obstacle to the diffusion.

- $\quad$ Ethical/Cultural issues: the production or consumption of particular foods could be taboo in some cultures and religions and thus carry ethical implications (e.g., consumption of lab-grown meat).

- Production price: current production price, ranging from affordable to very expensive (where 1 = very expensive and $4=$ affordable). This data does not refer to a particular regional area.

- Consumer price: current consumer retail price, ranging from affordable to very expensive (where 1 = very expensive and $4=$ affordable). This data does not refer to a particular regional area.

- Processing difficulty: the number of operations needed and their complexity, ranging from very easy to very difficult (where 1 = very difficult and $4=$ very easy).

- Sustainability: it includes the environmental sustainability of production and processing methods (including industrial processing), or any benefits and downsides.

- Chance of diffusion: the possibility that the product will become part of daily diets in the coming years, according to current scientific research, consumers' perception, present market dynamics, and forecasts. 
Based on the considerations in Table 1—which have a purely demonstrative purposeit is evident microalgae are a promising superfood because they are natural and sustainable products already partially used in our diets (and with a diversified use throughout history). Their nutritional value is high in the face of limited production costs. Although palatability could be a barrier to adoption, microalgae consumption does not imply ethical-cultural issues. The chances of microalgae becoming part of our diets in the coming years are high.

Table 1. The most promising novel superfoods: a comparison ( $1=$ very poor; $4=$ very good $)$.

\begin{tabular}{|c|c|c|c|c|c|c|c|}
\hline & $\begin{array}{c}\text { Meal } \\
\text { Replacements }\end{array}$ & $\begin{array}{c}\text { Plant-Based } \\
\text { Meat }\end{array}$ & $\begin{array}{c}\text { Lab-Grown } \\
\text { Meat }\end{array}$ & Insects & Mushrooms & Seaweed & Microalgae \\
\hline Type & synthetic & synthetic & synthetic & natural & natural & natural & natural \\
\hline $\begin{array}{l}\text { Presence in } \\
\text { Diets }\end{array}$ & yes & partly & no & partly & yes & yes & partly \\
\hline Nutritional Value & 3 & 3 & 2 & 3 & 3 & 3 & 4 \\
\hline Acceptance & 3 & 3 & 2 & 1 & 4 & 3 & 3 \\
\hline Palatability & 4 & 3 & 3 & 2 & 4 & 2 & 2 \\
\hline $\begin{array}{c}\text { Ethical/Cultural } \\
\text { Issues }\end{array}$ & no & no & yes & yes & no & no & no \\
\hline Production Price & 3 & 3 & 1 & 3 & 3 & 3 & 3 \\
\hline Consumer Price & 2 & 2 & 1 & 4 & 3 & 3 & 3 \\
\hline $\begin{array}{l}\text { Processing } \\
\text { Difficulty }\end{array}$ & 2 & 2 & 1 & 3 & 3 & 4 & 4 \\
\hline Sustainability & 2 & 2 & 2 & 3 & 4 & 4 & 4 \\
\hline $\begin{array}{l}\text { Chance of } \\
\text { Diffusion }\end{array}$ & 4 & 4 & 2 & 2 & 4 & 4 & 3 \\
\hline
\end{tabular}

\subsection{Spirulina: A Solution to Food Shortage}

With regards to the several efforts of classification, experts recognize two main groups of algae: macroalgae and microalgae. Macroalgae are represented by diverse kinds of photosynthetic marine, eukaryotic, and multicellular organisms (e.g., seaweed). Microalgae are instead mostly single-celled organisms and oxygenic photosynthetic bacteria (e.g., cyanobacteria) [16]. Among the thousand microalgae species, Spirulina (Arthrospira platensis) is one of the best known. It is a multicellular filamentous cyanobacterium characterized by a spiral shape [17] which has been growing spontaneously for millions of years in Africa and South America [18]. Nowadays, it is usually harvested in large-scale plants, and more than $70 \%$ of the global Spirulina market is for dietary supplements, cattle feed supplements, and human consumption [19]. In most cases, Spirulina is added as an ingredient to dry and fresh pasta, bread, and other baked goods, but also to seasoning, chips, cheese, chocolate, ice-creams, candies, and honey. Spirulina is added to many drinks too.

Spirulina is considered a superfood because of its chemical composition [20]. It has a high content of high-quality proteins, equal to about $60-70 \%$ of its dry weight, and it contains a balanced dose of carbohydrates (12-25\%), lipids, and essential amino acids (18\%). It is also a rich source of vitamins (Vitamin E, Vitamin B12) and pigments (Carotenoids, Chlorophyll a, Phycocyanin). Spirulina contains many minerals, including calcium, magnesium, phosphorus, sodium, potassium, and iron, all of which are more easily absorbed by the body. The protein content is much higher than other foods (Figure 1) [21].

Spirulina "can be cultivated on marginal, unusable, and non-fertile land. Its rapid growth means Spirulina protein needs 20 times less land than soybeans, 40 times less than corn, and 200 times less than beef cattle. Spirulina offers more nutrition per acre than any other food, but does not require fertile soil; Spirulina proteins uses $1 / 3$ the water as soy, $1 / 5$ as corn, and only $1 / 50$ the water needed for beef protein" [22] (p. 17). The 
costs for its production are relatively low. For this reason, many experts believe that Spirulina may be the perfect food to sustain a world in crisis [23]. In 1947, a report from the Food and Agriculture Organization of the United Nations suggested the need for agricultural development to cope with an increase in the world population in the following decades [24]. "The food policy establishment was quite taken with algae. With half of the people of the world hungry, [ . . . ] and farmers already struggling to grow enough food, significant doubts began to emerge about the ability of conventional agriculture to stave off catastrophe. Scientists believed that they would have to develop radically unorthodox food sources to feed a much more crowded world" [25] (p. 608). Thus, experts considered algae a possible remedy to a Malthusian catastrophe and a promising solution for the upcoming years. Among the factors that most influenced microalgal studies were the fear of food insecurity, the housing boom, and the rise of environmentalist movements in America [26]. In 1967, Spirulina was recognized as a 'wonderful future food source' by the International Association of Applied Microbiology [27], but the agricultural revolution, the adoption of new technologies and chemical fertilizers, and the development of birth control to curb population growth, dismissed the necessity of finding novel food sources to feed the world. Thus, research in this field decreased considerably.

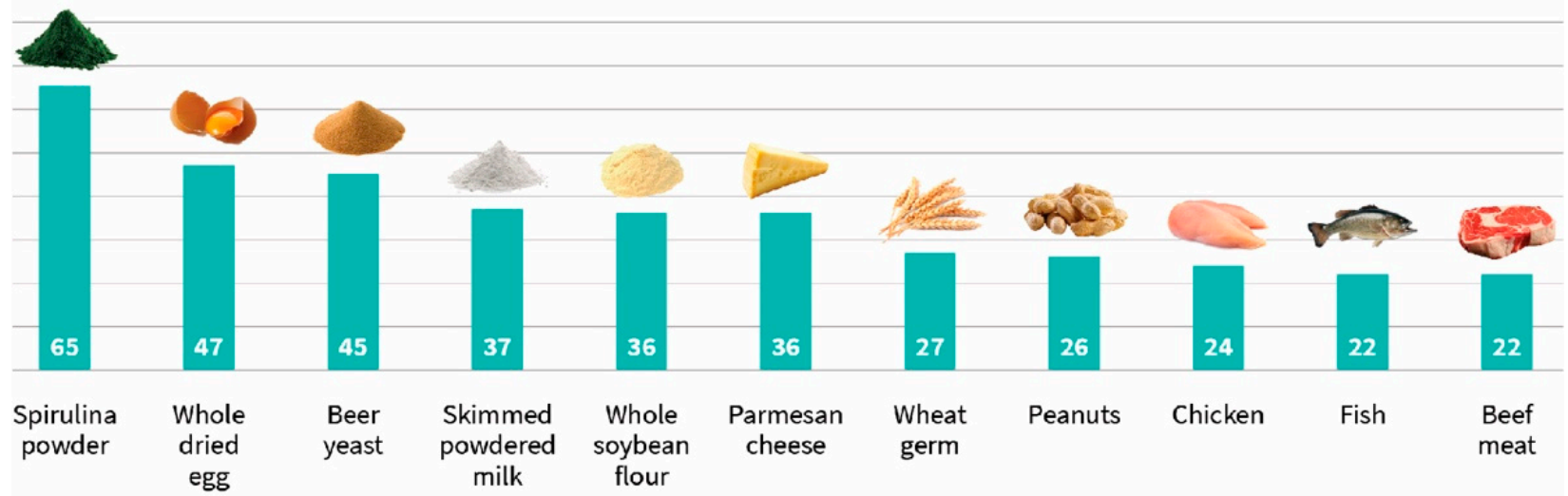

Figure 1. Quantity of Spirulina proteins and other foods. Crude protein percentage. Adapted from [21] (p. 12).

Nevertheless, over the past 40 years, numerous humanitarian and commercial projects which involved the cultivation of Spirulina have been implemented in developing countries, including Mexico, Myanmar, Thailand, India, Cambodia, Costa Rica, Ecuador, Togo, Chad, Madagascar, Niger, and Burkina Faso. The cultivation of Spirulina with traditional low-cost techniques proved to be an effective remedy against chronic malnutrition and an essential contribution to some regional economies [28]. FAO has noticed these kinds of projects and is now monitoring the investments and communication methods required, as well as the possibility of creating additional pilot projects with communities in developing countries [29]. This model has also been adopted in other countries: for instance, in France, there is a vast network of producers called 'Fédération des Spiruliniers de France' who grow Spirulina with artisanal practices and sell it in local markets. Their model could be virtually replicated everywhere.

\section{Food Safety Aspects}

Consumption of any food is not without risk, and even microalgae could cause harm. Studies on this topic are relatively recent, and there are no universal food safety regulations. "Only products from Arthrospira platensis have so far been cleared for consumption (United States of America, Australia, Canada and probably EC), under specific conditions, by public health authorities" [30] (p. 19). Nevertheless, if not adequately grown, Spirulina could be contaminated too. "The consumption of this cyanobacterium can induce abdominal pain, 
nausea, or flatulence when it is consumed for the first time. If Spirulina is infected with various contaminants from the water, toxins, heavy metals, or pollutants, it also gives rise to severe gastric perturbances" [31] (p. 15). Thus, it is recommended to research the source of Spirulina and to seek medical advice if it is eaten regularly because prolonged exposure to heavy metals is toxic. Fortunately, recent studies have shown that the vast majority of Spirulina on the market contains heavy metal levels within the recommended daily intake levels and is, therefore, considered to be a safe food [32]. Furthermore, the production of Spirulina in closed, controlled environments rather than open ponds could guarantee superior quality, mitigating the issue of contamination with cyanotoxins (e.g., microcystin) and other air-coming pollutants.

\subsection{Design and Microalgae}

This research delves into the relationship between design and phycology - the study of algae-by trying to answer two questions: 'Can the design discipline contribute to microalgal studies?' and 'How can design researchers contribute to foster the adoption of microalgae for food use?' To date, there is no word to define the unusual investigation area between these two fields that are so far apart. However, this area of study is more a research and practice niche within sustainable design, especially biodesign — an emerging design approach based on science that integrates the use of living matter within products, structures, and processes [33]. Artists, architects, and designers continuously update themselves with the latest technologies and innovations, and over the decades, they have challenged the previously accepted limits with their works. Among the several nature-based solutions that have been adopted so far (biocement formed thorough bacterial metabolic activity [34], 3D bioprinting [35], and mycelium-based products and structures [36], to name a few), designers are increasingly experimenting with algae and microalgae, for instance, with large-scale installations, new product designs, furniture, innovative bioplastic packaging, and energy and food systems. Accordingly, multifaceted research domains are opening up. Due to their ease of cultivation, high yields, and the limited amount of water and land need to grow-microalgae could play a pivotal role in novel solutions for human food production in the upcoming decades. Designers and chefs are collaborating to create innovative and futuristic microalgae-production devices. They are also experimenting with tasty new recipes to make microalgae more palatable and slowly change consumers' eating habits [37]. Microalgae could be useful not only on Earth but also in space. A new era of space exploration is upon us, and the colonization of other planets would require new approaches to design and food production. NASA is already working on this topic with designers and scientists [38].

Although the interest in microalgae is increasing in several fields, in the design discipline, the research is mainly linked to the practice. Scientific publications in the field of design are minimal. From research on Scopus, it emerged that 24,362 documents are mentioning the word 'microalgae' in the title, abstract, or keywords (data as at December 2019) (Figure 2). Of these, 9.4\% fall into the category 'Other,' which also includes the area of 'Arts and Humanities.' Within Arts and Humanities, there are only 18 publications $(0.07 \%$ of the total). Barely four of them include the word 'design' within the title, abstract, or keyword. An analysis of EBSCOhost Art \& Architecture Source shows similar results. From 1995 to 2019, only 34 documents mention the word 'microalgae'. Of these, 14 are articles in Academic Journals, mainly of architectural nature, while the remaining are articles on periodical magazines, principally with reviews of practice-based case studies. It is, therefore, evident that a gap in research needs to be bridged. This represents a unique opportunity in the advancement of knowledge and theory in this study field. Theoretical research must keep pace with practice, which shows unexpected solutions every day. The time has come to have a broader approach to the world of microalgae so that they will not only be used for technical and stylistic solutions but included in more comprehensive projects, vectors of innovation, sustainability, and well-being. Hence, the research between design and phycology is fresh and innovative. 


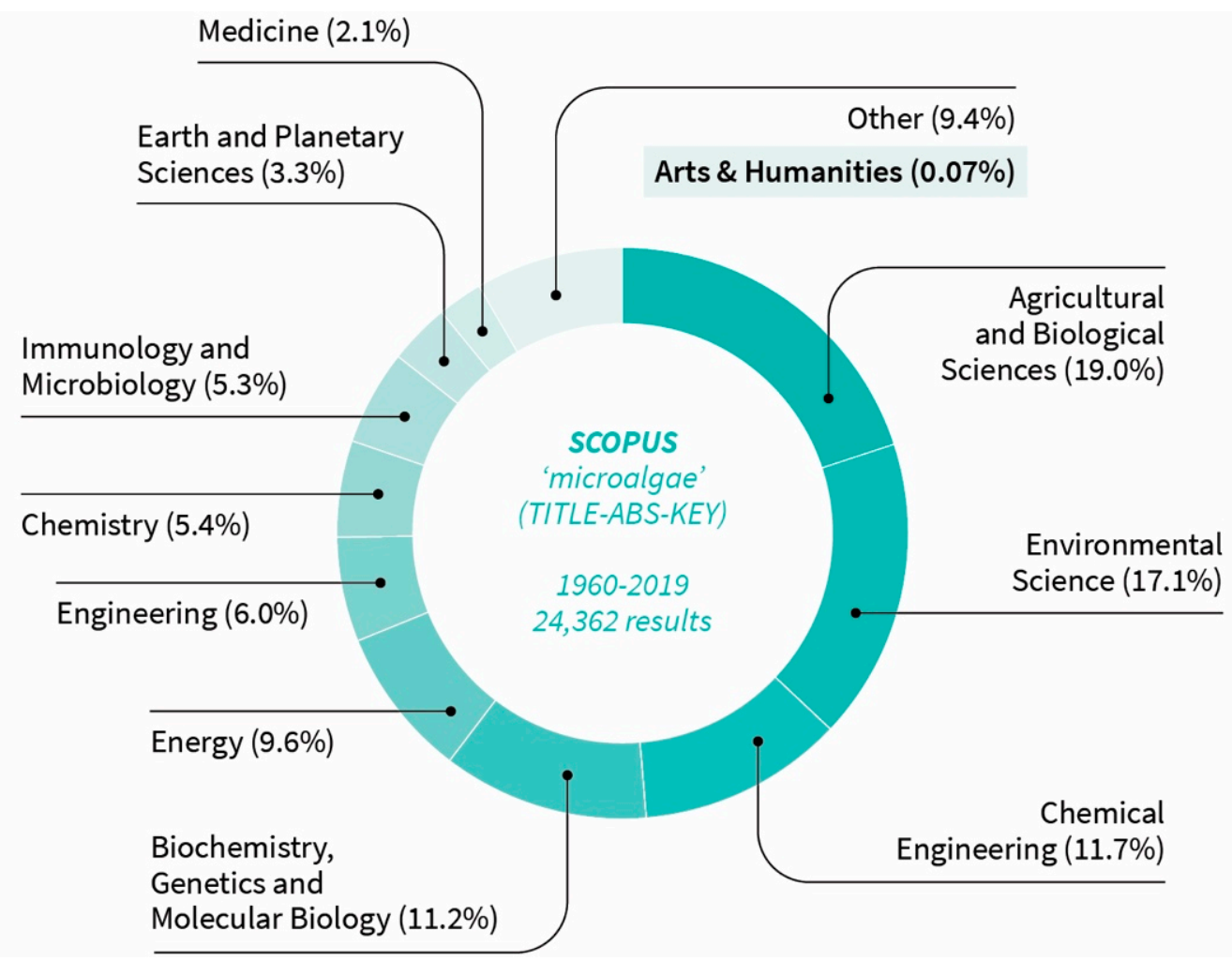

Figure 2. Scopus database. Documents by area, including the word 'microalgae' in the title, abstract, or keywords. Percentage of the total (24,362 results from 1960). Only 18 publications fall in the area of Arts and Humanities. Data as at December 2019.

\section{Research Method}

Design research is a challenging task requiring both theoretical abstraction and practical work to trace and define new potential applications and deliver a relevant academic product. "Even though the conditions that have initially framed the field of design have changed significantly and designers now work in a post-industrial, rather than industrial society, designers are still perceived as people who 'make' rather than people who 'think'" [39] (p. 190). A practice-based approach was chosen for this study to advance knowledge about and within the practice and present valuable theoretical results. Practicebased research is, indeed, important in an academic environment because it contributes to knowledge through artifacts and substantial textual contextualization [40], allowing the combination of different research tools. The practice-based work in this study aims to facilitate microalgal learning in design, communicating its principles, and acting as a fundamental part of a knowledge-building process. The main objectives of the work are:

- Fill the practice gaps.

- Leverage innovative design possibilities.

- Experiment with the design of new technical solutions.

- Create one or more devices for Spirulina production food use.

- Hypothesize innovative product-service systems which use microalgae as a vector for healthy and sustainable growth.

- Test and validate the results to guarantee scientific rigor and objectivity.

- Define a theoretical framework.

The project phase took place in Beijing over a period of five months and adapts to the Chinese context. The design process consisted of a home-experiment to learn how to grow Spirulina, a survey to explore people's propensity to eat microalgae, a workshop to gain qualitative data, a product development phase, a validation test session. 


\subsection{Case Studies Analysis}

An earlier methodological investigation [41] explored the topic of microalgae in urban contexts around the world: city-scale architectural installations, buildings, and pavilions showcasing the properties of microalgae, but also social design activities. The research unveiled that these projects are scarce, temporarily limited, and with significant limitations. In addition, it presented compelling design possibilities to the benefit of local communities and suggested how to approach similar projects. Parallelly, a case studies analysis was conducted to investigate the most prominent design experimentations involving microalgae in the last decade. The analysis was an iterative process characterized both by desk research on relevant documents, including scientific publications, newspaper articles, and blog posts, as well as interviews and field trips. A total of 20 case studies were identified (Appendix A). These were innovative small-scale solutions coming mainly from the world of design practice that used microalgae creatively. Later, seven projects falling within the sphere of home product and furniture design were cherry-picked because of their capacity — or potential ability—of yielding biomass for food use. Even if they were semantically similar to each other, they did not compete in a particular market but work in a complementary manner. Different product features were taken into consideration to provide an objective comparison and have been estimated on a scale of $1-4$, where 1 is generally very poor, and 4 is very good (Table 2). These are:

- Main scope: The primary function of the device.

- Dimensions: The physical dimensions of the product, ranging from contained to substantial, where $1=$ substantial and $4=$ contained.

- Photobioreactor (PBR) shape: The shape of the production tank (flat-panel, tubular, tank, etc.).

- Production system: Whether the system is open or closed.

- Harvesting system: Typology and mechanism of the harvesting system.

- Productivity: The relative amount of biomass produced in a given timeframe.

- Usability: Ease of use or high-grade performances.

- Maintainability: If the product can perform with minimum maintenance, or if the maintenance is easy to accomplish (e.g., cleaning the tank).

- Cost-effectiveness: The production/manufacturing/replicability price given the biomass productivity.

- Open-source: Whether the project is available in open-source collaboration and peerproduction is incentivized.

This case study analysis laid the foundation for the next step of the practice-based research. The analysis discovered that microalgae are undoubtedly appealing to designers. Although many design objects have an unusual aesthetics and are often disconnected from their context, they have incredibly innovative attributes. Real-world cases' comprehension is likely to involve important contextual conditions pertinent to future design outcomes [42]. Therefore, the outcome of this research is inspired by the products illustrated above and tries to improve some of their characteristics by creating new meanings.

\subsection{Experiment}

A homemade production was set up to gain practical knowledge about Spirulina cultivation. The experiment lasted for one month and consisted of running a rudimentary, yet fully-functional, home photobioreactor- "an enclosed, illuminated culture vessel designed for controlled biomass production" [43] (p. 2349). The goals of the experimentation were:

- practical hands-on with a microalgae culture;

- comprehension of the farming process;

- identification of potential troubles for non-experts growers;

- supply of the necessary components for the construction of a photobioreactor;

- gaining insights on the operational requirements of a photobioreactor. 
Table 2. Comparison of selected product design experimentations $(1=$ very poor; $4=$ very good).

\begin{tabular}{|c|c|c|c|c|c|c|c|}
\hline & $\begin{array}{c}\text { Algae } \\
\text { Curtain }\end{array}$ & $\begin{array}{l}\text { Eco-Friendly } \\
\text { Lamp }\end{array}$ & $\begin{array}{l}\text { Living } \\
\text { Things }\end{array}$ & Farma & Spirugrow & Symbiont & The Coral \\
\hline Main Scope & biofuel & $\mathrm{CO}_{2}$ capture & food/biofertilizer & drugs & food & $\begin{array}{c}\mathrm{CO}_{2} \\
\text { capture }\end{array}$ & food \\
\hline Dimensions & 1 & 2 & 2 & 3 & 3 & 2 & 2 \\
\hline PBR Shape & tank/various & tubular & various & tubular & tank & tank & flat-panel \\
\hline Production System & closed & closed & closed & closed & closed & closed & open \\
\hline Harvesting System & manual & $\begin{array}{c}\text { semi- } \\
\text { automatic }\end{array}$ & manual & $\begin{array}{c}\text { semi- } \\
\text { automatic }\end{array}$ & $\begin{array}{c}\text { semi- } \\
\text { automatic }\end{array}$ & manual & manual \\
\hline Productivity & 1 & 4 & 2 & 3 & 3 & 1 & 2 \\
\hline Usability & 1 & 1 & 2 & 3 & 3 & 2 & 1 \\
\hline Maintain-ability & 1 & 4 & 2 & 3 & 3 & 1 & 2 \\
\hline Cost-effectiveness & 2 & 4 & 1 & 3 & 2 & 1 & 1 \\
\hline Open-source & no & no & no & yes & no & no & no \\
\hline Educational Value & 2 & 1 & 3 & 3 & 2 & 3 & 4 \\
\hline
\end{tabular}

The following elements were needed: a container in which to place a substrate (water), an energy source (light), a way to mix the culture (an air bubbling device), a supply of nutrients (nitrogen and phosphorus), a temperature control device (digital thermometer), a temperature regulation device (aquarium heater), and an algae cell inoculum. These were all sourced online (Appendix B). The experiment can be considered as an early-stage prototype, reasonably functional even if with substantial flaws: the setting up required several components that were reused and adapted later on in the design phase. The aquarium was placed close to a window but not exposed to direct sunlight. The air pump, the bubble tube, and the digital thermometer were then installed. The aquarium was subsequently filled with $2 \mathrm{~L}$ of drinking water, and the air pump was powered on to aerate and circulate the culture. The tube has been arranged to optimize air and water flows. One bag of culture salts was poured into the water, together with the nutrients. The starter formula was stirred with clean hands until completely dissolved. Consequently, the Spirulina inoculum was added. The LED light was positioned and activated at alternate times, and the algae have been let grow for $48 \mathrm{~h}$. The total water volume was increased by $10-20 \%$ daily, trying to keep a similar density, until reaching the total volume of $16 \mathrm{~L}$. A smaller backup culture was set in case of problems with the main one.

The algae were allowed to grow for two weeks, and the $\mathrm{pH}$ levels were controlled periodically. A heater was placed in the aquarium to optimize the temperature of the culture. The clumps that were building up, especially on the surface, were easily removed with a colander, and the optimal culture density was verified through the use of a Secchi stick. When the instrument indicated $10 \mathrm{~mm}$-a rather shallow depth-the culture was very dense and ready to be harvested. The thick blue-green paste was filtered with the sieve: a final rinse with fresh water washed away alkali salts and bacteria. Finally, with the help of a spoon and careful attention not to break the sieve, the experimenters collected the fresh biomass in a small bottle, resulting in a total of around $10 \mathrm{~mL}$. The remaining water was mainly intracellular. Visual documentation of the steps of the experiment is illustrated in Figure 3.

Growing microalgae at home was a stimulating practical experiment. The culture process itself was not complicated: it required minimum maintenance with regular commitment. Supposedly this experiment is, to a certain extent, easy to replicate even for non-experts. However, step-by-step instructions, and primary education on the topic are essential requirements. Without this support, the culture may die or be contaminated by external agents, hindering growers in their efforts to produce microalgae. No particular 
complexities have been identified during the process, and this experimentation achieved the prefixed objectives while guaranteeing a fair amount of living culture for the next steps of the project.

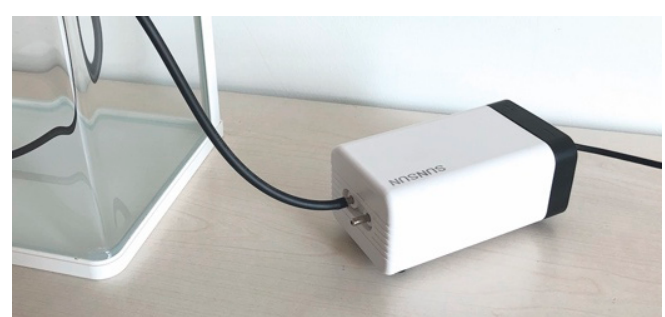

(a)

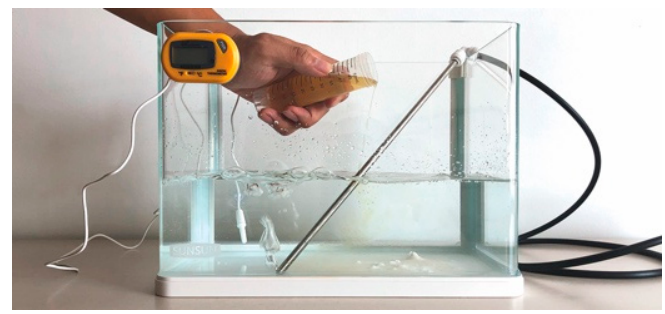

(c)

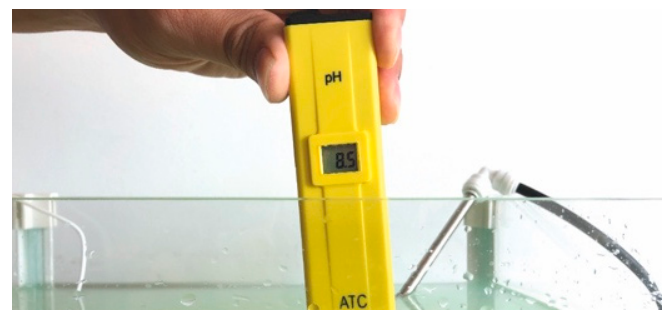

(e)

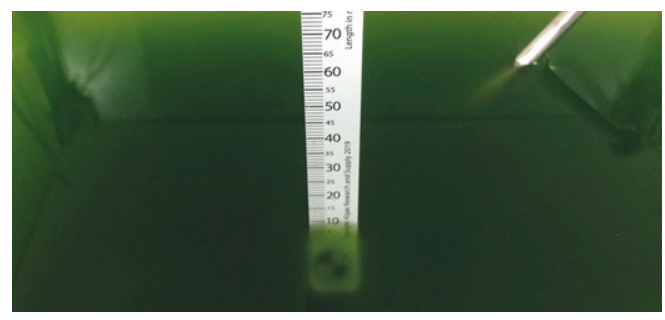

$(\mathrm{g})$

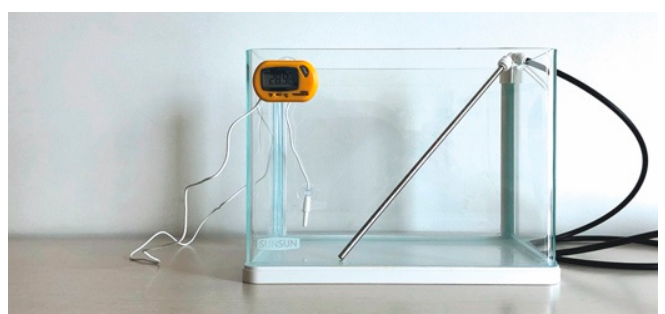

(b)

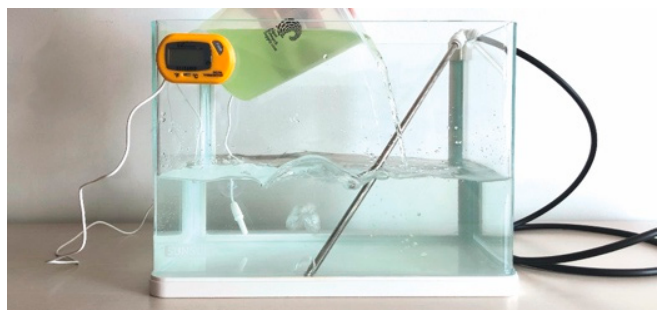

(d)

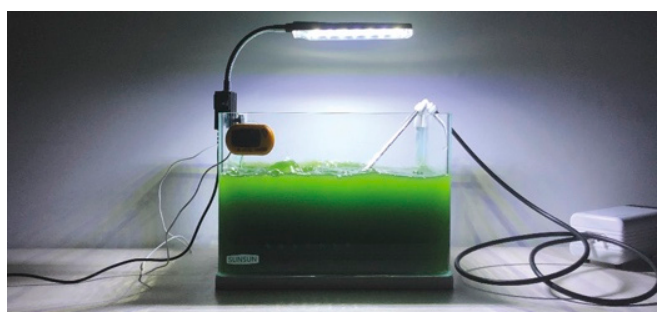

$(\mathbf{f})$

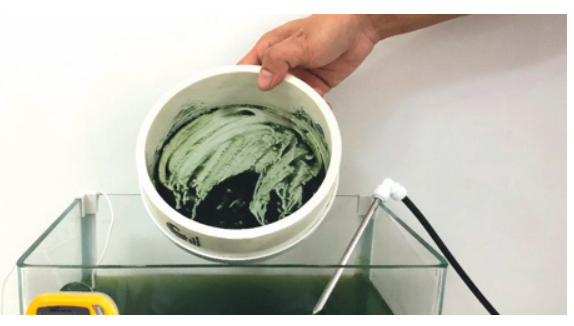

(h)

Figure 3. (a) Positioning of the aquarium and installation of the air pump; (b) installation of the bubble tube and positioning of the digital thermometer; (c) filling with drinking water, actioning the aeration system, and adding the culture salts and nutrients; (d) adding Spirulina culture; (e) reaching the maximum volume and periodical control of pH levels; (f) growth for two weeks; (g) verification of optimal culture density with the Secchi stick; (h) filtration, final rinse, and collection of the biomass.

\subsection{Survey}

The purpose of this survey was to document people's opinions, attitudes, and previous experiences with food and microalgae. Mainly, the goals were:

- collect quantitative data through the involvement of a large pool of people;

- understand food purchase behaviors and eating routines; 
- gaining insights into consumers values;

- explore participants' propensity to change food habits, and try new foods;

- assess their knowledge about microalgae;

- arouse their curiosity in participating in thematic tasting sessions;

- evaluate the interest in cultivating microalgae.

The online survey included multiple-choice options, behavioral scales, Likert scales, and a few open-ended questions to gain qualitative data. The link was spread digitally, and it rapidly gained popularity. A total of 504 people answered during a period of 15 days. Most of the interviewed were Chinese aged between 18 and 30 years old $(70 \%)$ living in firsttier cities like Beijing and Shanghai. Around 30\% of the respondents defined themselves as 'meat enthusiasts', a rapidly-rising trend that is strictly connected to the higher purchasing power of the consumers, who are embracing Western diets and lifestyles [44]. However, more than $20 \%$ believed their eating habits had to change. Interviewees were asked if they knew something about Spirulina, but almost half had never heard of it. Therefore, after receiving a brief introduction about microalgae's properties, participants were questioned if they were willing to eat Spirulina in the future. Far beyond expectations, $60 \%$ declared they were so inclined: most people indeed would have loved to try functional, healthy drinks and both salty and sweet foods like pasta, chips, and seasonings. Despite that high interest, taste, smell, appearance, and color were still considered the main barriers to adoption.

The survey was essential in this first design phase to define the future steps of the research. Participation in the survey of young well-educated respondents suggests youngsters may be more interested in healthy nutrition than older people, at least in China. Millennials (Generation Y) and Centennials (Generation Z) could, therefore, be the right target for the design of innovative food products and services. Microalgae production at home and in local communities were considered solutions with great potential, even if with some substantial concerns (e.g., easiness, time, commitment, maintenance, price, safety). Survey data interpolation was useful for the definition of potential personas and the organization of a thematic workshop.

\subsection{Workshop}

The workshop engaged 26 people, mainly aged 23-30 years old and with previous knowledge of products and services conceptualization. Design researchers, academics, and professional award-winning practitioners took part in the workshop too. The invitees were representative of those respondents who showed greater interest in the online survey. The goals of the workshop were:

- provide invitees with fundamental information about the benefits of microalgae and how to cultivate Spirulina;

- understanding their interest in consuming or harvesting microalgae for food use;

- get quantitative data on the palatability of proposed recipes;

- $\quad$ validate the results of the online survey;

- gaining insights for the design of product-service systems involving microalgae.

The event was structured into three parts: after a short introduction, the guests tasted selected Spirulina-based foods and drinks, prepared in collaboration with a local pastry shop. Later, the participants learned how to cultivate microalgae through playful activities. Ultimately, the participants envisioned hypothetical services and products involving microalgae. Participants were required to work in groups and present their outcomes to the audience, activating a lively dialogue.

\subsubsection{Tasting Session}

Participants were curious to try out new recipes made with microalgae. Before, more than half of the workshop attendees argued the smell could have been a barrier for them and prejudiced the taste. Attendees then tried a drink, two savory products, and a dessert (Spirulina lemonade, Spirulina crackers, and Spirulina chocolate cookies). These snacks were 
the fruit of a collaboration with a local bakery. Much space was given to the chef's creativity, who managed to enhance the flavor of Spirulina without disguising it. The chef also worked on the color and intensity of the green, trying to make the product palatable and visually appealing. Participants rated each recipe on a Likert scale from 1 to 5 , where $1=$ very bad and $5=$ very good. The aspects to evaluate were the appearance, the smell, and the taste (Figure 4). Participants also expressed an overall subjective opinion and added qualitative comments: the results were encouraging. Contrary to previous convictions, participants positively evaluated each recipe. Most of them were also willing to prepare these recipes at home or eat them again in a restaurant.

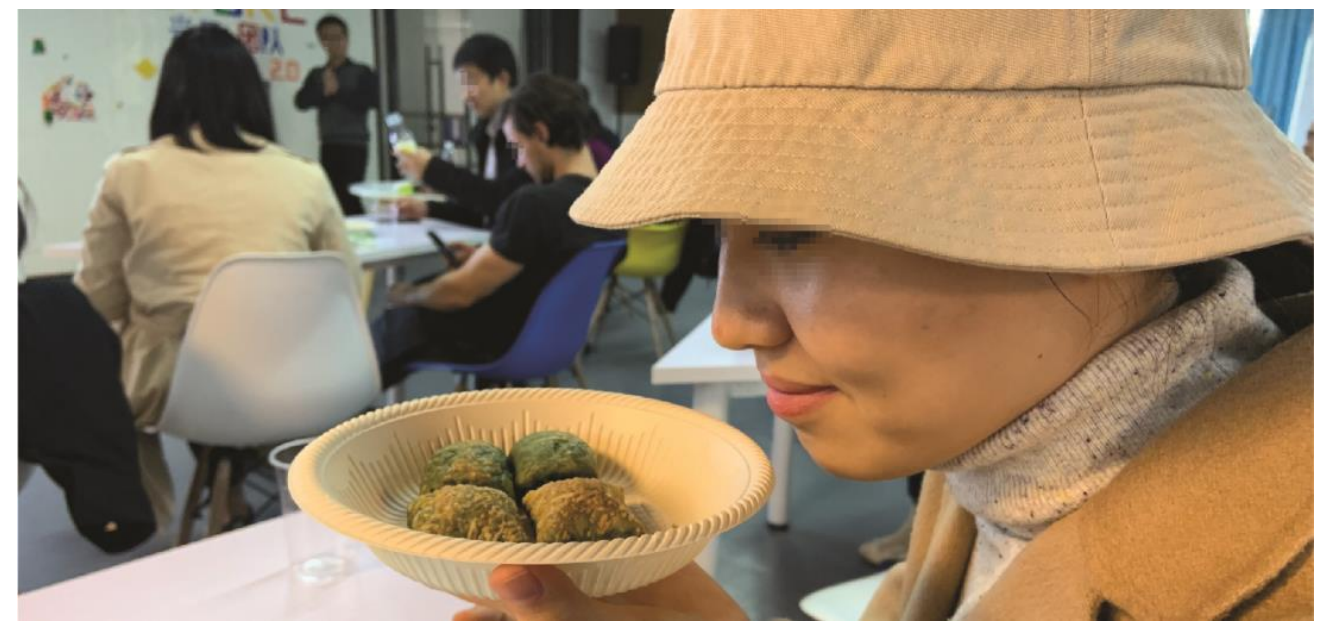

Figure 4. A participant smells a plate of freshly baked Spirulina crackers during the tasting session.

\subsubsection{Design Session}

This part of the workshop started with a brief talk and demonstration on innovative ways of cultivating Spirulina at home or in open spaces. The most recent product design experimentations and urban installations were presented. A focus was also made on photobioreactors, their main characteristics, and functions. Subsequently, participants were asked to express their opinion on the features that a Spirulina production device should have and the type of functions they would like to be automated. Moreover, attendees were presented with three mood boards to identify the most suitable look and feel for possible designs. The next two activities aimed to design a system map of a hypothetical microalgae production/distribution service and sketch a device that would fit in it. For the service design phase, 42 small adhesive cards divided into six categories were provided to the groups. These were intended to be placed on a paper sheet and connected to show material, service, financial, and information flows. The card set was designed specifically for the event, while the toolkit taken as a model was initially devised by Emili [45] for her doctoral thesis. It has been adapted and simplified in some parts (Figure 5). The tool proved to be effective and easy-to-use.

Later the groups made some sketches, hypothesizing design devices for microalgal cultivation to fit their previous system maps. Each group presented the outcomes of their work, and an engaging open dialogue took place. Despite the prevalent opinion emerging from the survey that residential communities would not be interested in cultivating Spirulina, 5 out of 9 proposals involved schools, universities, or residential communities, volunteering activities, and engaging experiences. Other solutions included home-production devices.

\subsection{Product Development}

The analysis and classification of the case studies, the results of the online survey, and the workshop outcomes set the foundation for the product development phase, a salient step in the research process with the aim to bridge the gaps and create innovative product-systems. The actionable principles for designing small-scale products and 
urban installations involving microalgae proposed by Peruccio and Vrenna [41] were used and re-adapted with due considerations. Two diametrically different, still complementary, Spirulina-production photobioreactors were designed: a small device to be used in a domestic space and a larger public-use installation. The home device is conceived to regularly yield microalgal biomass sufficient to cover a personal recommended daily dose. Its design is modern and straightforward. For the public device, versatility was a priority. Thence, the design is modular and has many visual, dimensional, and technical similarities with other common elements found in cities, such as parcel drop-off points and vending machines. A requirement-performance analysis [46], consisting of interpreting the users' needs into practical features, was conducted for both devices. Defining these needs was of fundamental importance to take objective decisions related to the project's technical, stylistic, and semantic aspects.

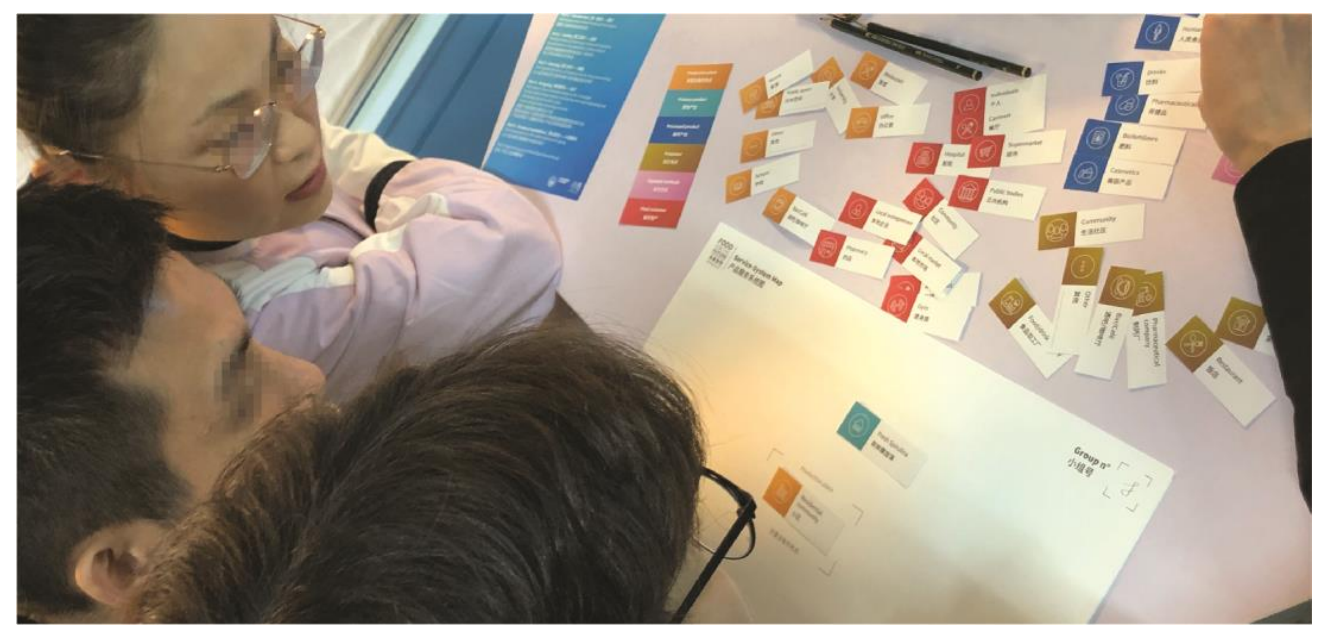

Figure 5. Participants using the card set as a tool to envision innovative product-service systems.

\subsubsection{A Home Device}

Working on the development of the home device was a challenging activity. The design process was not linear and required several corrections. Two early versions of the so-called 'Algae Grower' were realized. Version 1 was visually and technically rougher. It was made up of hand-cut PVC layers, screwed or glued together. The choice to work with multiple overlapping surfaces was dictated by the necessity to make small extemporary modifications (e.g., holes for the buttons, grooves for the cables). As for the internal components, this version included a considerably powerful air pump, which proved to be decidedly noisy and oversized and therefore not suitable for domestic use. Concerning the biomass harvesting system, the initial solution exploited gravity to collect fresh Spirulina in a small container. The upper part of the device and the lighting system were not taken into account in this version.

Version 2 had a much higher level of detail, and the internal and external structures were redesigned from scratch. 3D printing technique was used to realize them quickly. The powerful air pump was changed in favor of two smaller and quieter ones; the resulting free space permitted to add one more water pump, therefore improving the Spirulina extraction system. The internal structure was divided into distinct spaces for electrical components and water pipes to avoid possible short-circuits. In this phase, an assembled LED lamp with a matte surface finish was used for lighting. The lamp was placed inside a transparent tubular profile in the center of the tank. Although the lighting effect was pleasant, the intensity seemed insufficient to ensure maximum illumination of the culture. The top of the device was improved with a small removable lid. The 3D printed structure showed to be very strong but with an unattractive surface finish. Figure 6 shows the two preliminary versions of the Algae Grower. 


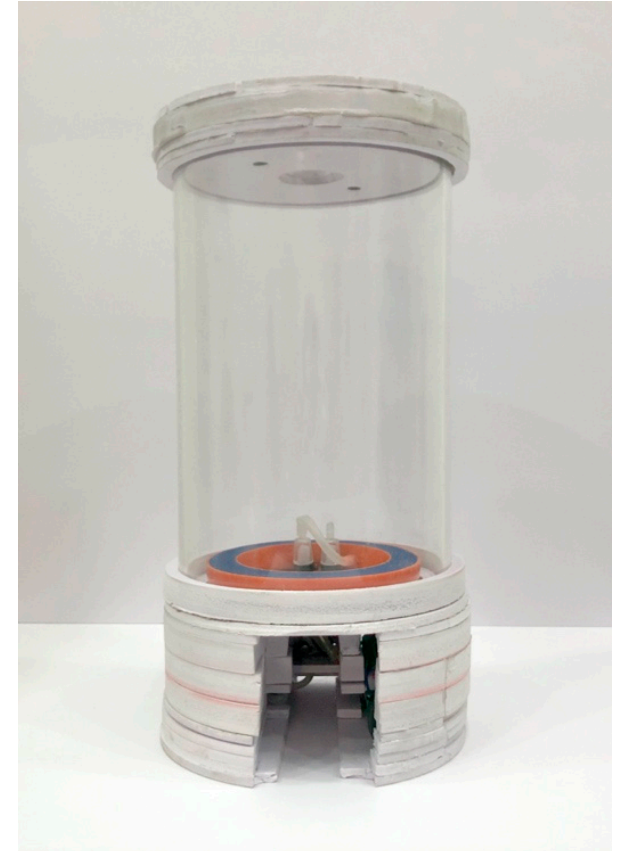

(a)

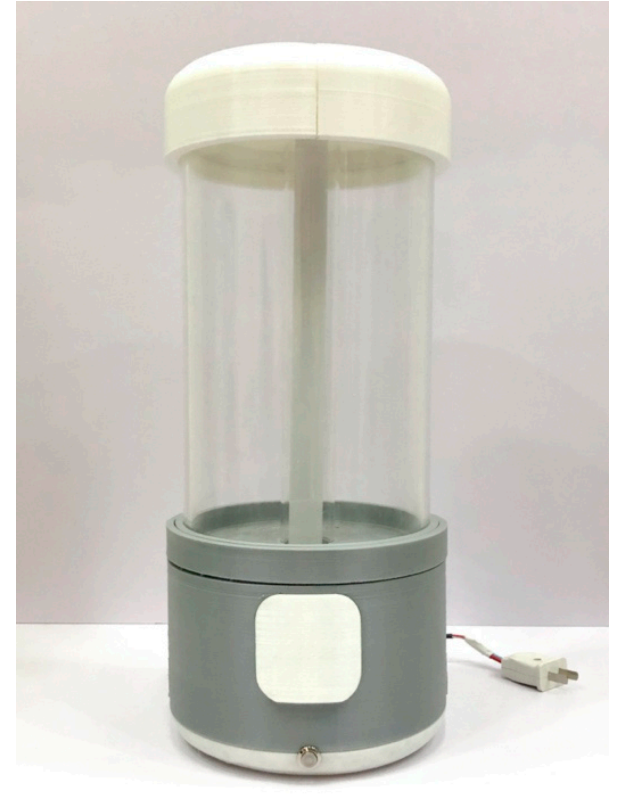

(b)

Figure 6. (a) The Algae Grower: version 1; (b) the Algae Grower: version 2.

\subsubsection{A Modular Public Installation}

Meeting the needs of cities and citizens requires an inclusive approach, acting on different dimensional scales and fields of application to fill the lack of urban products and services for microalgal biomass production and distribution. The public installation, an innovative device that relies on engineering and biological expedients, was named 'Algae Station.' Unlike the Algae Grower, the development of the Algae Station remained at the conceptual phase. The requirement-performance Table 3 sums up the envisioned requirements for use, operation requirements, production requirements, and environmental requirements. For each of these sections, the user needs are highlighted, to which the object responds with specific performances. The main features of the Algae Station are its modularity and versatility. The device can be configured to be placed, for instance, in a public square, a community space, a shopping center, or a school.

Table 3. The requirement chart of the Algae Station.

\begin{tabular}{lll}
\hline & Requirements & Performances \\
\hline Requirements for Use & Safe & Anchored stable structure. Smooth edges and corners. \\
& Simple & Easy to interact with. Use of few colors and materials. \\
& Productive & Guarantee high yields while assuring freshness. \\
& Modular & Possibility for multiple configurations. \\
& Contextualized & Peculiar, still familiar appearance. \\
& Educative & Provide environmental benefits information. Arouse curiosity. \\
& Shared & Multiple ways of use. Universal accessibility. \\
\hline Operation Requirements & Movable & Easy to transport single parts. Facility to be assemble on-site. \\
& Maintainable & Simple operations. Washable in all parts. \\
& Simple & Basic production techniques. \\
& Economic & Cheap to manufacture even in small-scale, local productions. \\
& Resistant & Resistant to all weather conditions. Vandal-resistant. \\
& Efficient & Integrated systems for energy control and self-sustainability. \\
& Durable & Long-lasting and strong, hard to break materials. \\
\hline
\end{tabular}




\section{Results}

This research's outcomes are the starting point for further studies and practice and are significant because of their applied and academic relevance. The results include the artifacts and services prototyped and conceptualized during the development phase and a theoretical framework within which design projects involving the use of microalgae can thrive. Other designers approaching this topic could learn from the artifacts and use the framework as a reference.

\subsection{The Algae Grower}

The Algae Grower is a fully working prototype of a home device for the production and semi-automatic collection of fresh Spirulina (Figure 7). It can yield enough algal biomass to satisfy more than the daily needs of an average adult or a small family. The device is intended to be used in the kitchen, and despite the technical complexity, to be rather easy to operate. Drawing inspiration from existing design projects, it adopts the same working principles of a photobioreactor. However, it differs from them because of the contained dimensions, the usability and maintainability, the cost-effectiveness, and the high educational value. Unlike other goods for commercial use, the Algae Grower blueprint and parts list have been made available online for free [47]: thanks to the open-source the device can easily be replicated.

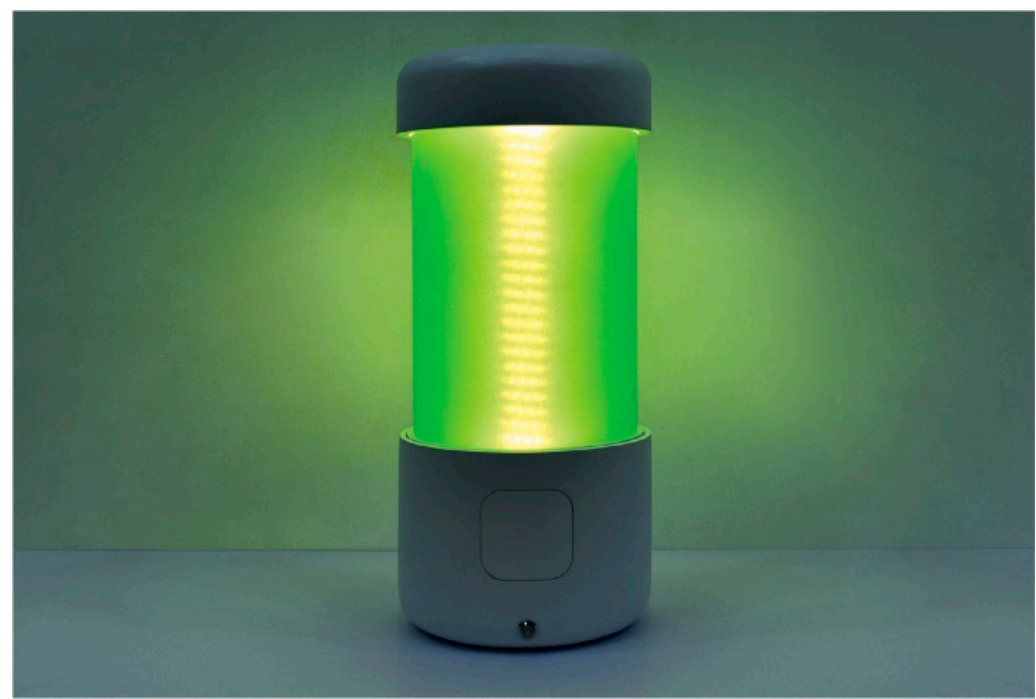

Figure 7. The Algae Grower. Copyright 2020 by Li Tian.

Premium finishes characterize the high-fidelity prototype. The structure is in ABS, an easy-machined, high-impact strength, and low-cost, rigid plastic material. The ABS was $\mathrm{CNC}$ milled and coated with a washable, water-resistant white paint, safe for food use. The structure is composed of:

- an upper cover to protect the culture from external contamination;

- a base for the tank, perforated to allow the passage of water and air;

- the support for the internal components (e.g., air and water pumps, electric boards). This part consists of 5 pieces, connected by interlocking. It also holds the drawer for collecting Spirulina;

- the drawer, which can be split into parts, and its track slides;

- the outer shell of the lower main body, with openings for the buttons and the drawer.

The axonometric exploded view in Figure 8 shows all the parts. A detailed list of the components used in the prototype can be found in Appendix C. 


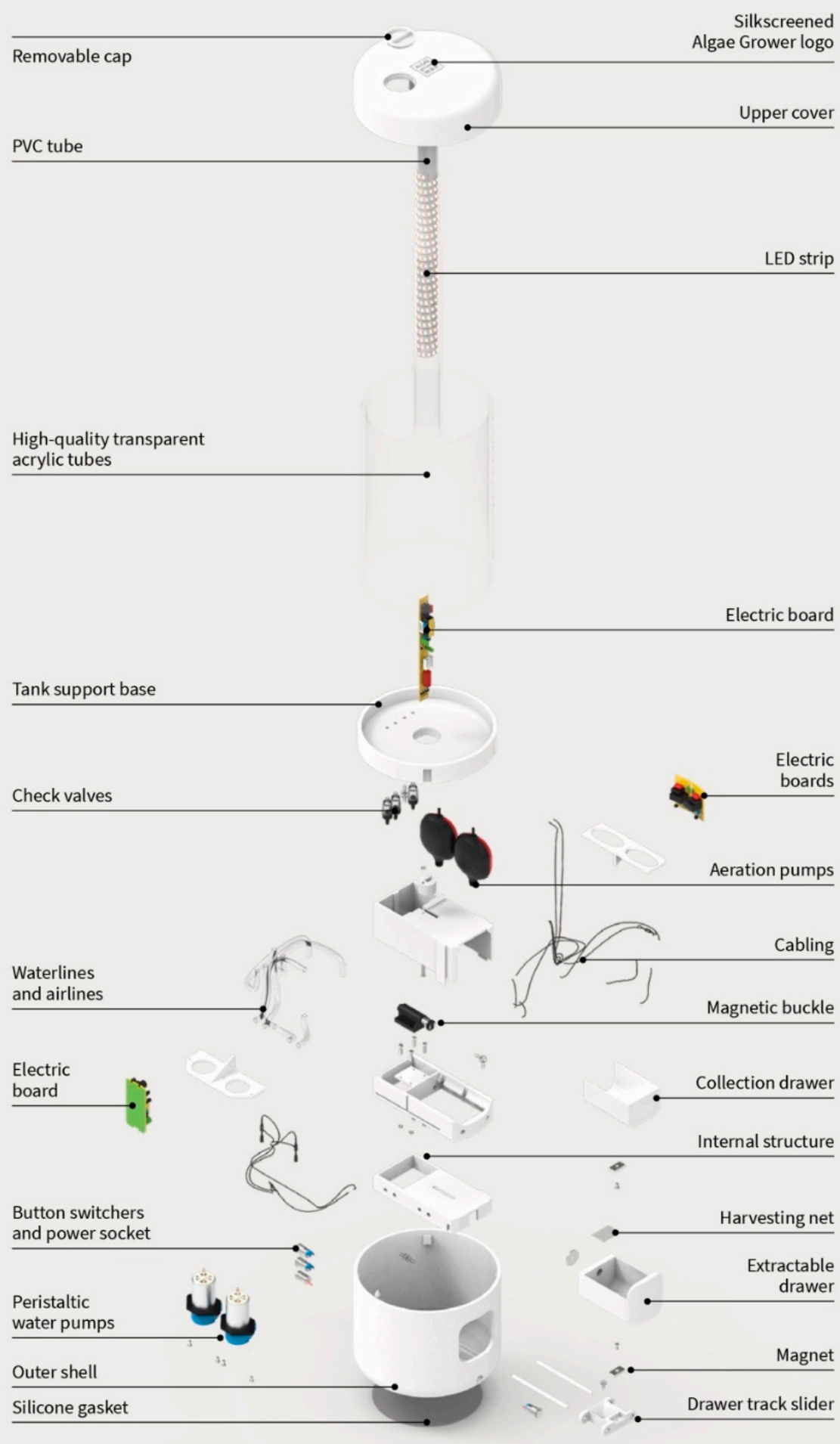

Figure 8. Axonometric exploded view of the Algae Grower and its internal components.

The overall size of the device is $40 \mathrm{~cm}$ high by $18 \mathrm{~cm}$ wide, and the tank has a volume of $4 \mathrm{~L}$. Its tubular shape ensures a good recirculation of air and water flows-uniformly moving the culture-and allows easy cleaning of external and internal surfaces. Highquality acrylic was chosen over glass for the main tank because it is a cheaper and more resistant material. The lighting of the culture is provided by an LED strip wrapped on a tube. The central positioning is for uniform illumination. The top cover protects from 
possible external contaminations (e.g., dust). For quick inspections, such as checking the density of the culture or adding nutrients, a user can utilize a small removable cap without lifting the whole lid. Two air pumps provide a regular flow of oxygen and $\mathrm{CO}_{2}$. A water pump extracts fresh biomass from the tank, which is collected in a drawer located underneath. The second pump operates simultaneously but with an inverse flow, enabling the filtered water-still rich in nutrients-to get back into the tank. The front drawer is composed of several parts for an effortless replacement of the filter cloth in case of damage. It is also entirely removable from the main body for comprehensive cleaning. The prototype can be controlled with just three switches: the front one is for operating the water pumps to collect Spirulina, and the rear buttons are for switching the lighting and the air system on and off. Icons were laser engraved on the buttons to facilitate the understanding of their functions.

This device's design responds well to the characteristics that, according to most of the survey respondents and workshop participants, a Spirulina home-production device should have: functionality, safety, ease of use and maintenance, aesthetic. Blog articles about this project have been published on international design and lifestyle websites that raised the interest of academics, scientists, professional designers, makers, and chefs from different parts of the world [48-51]. Some of them showed interest in replicating the device.

\section{Validation Tests}

The purpose of this phase was to validate the functions of the Algae Grower by verifying the device's ability to produce and collect fresh biomass, checking that components worked correctly in routine daily operations, gaining feedback from users, and identifying both limits and possible improvements. A first test consisted of using the high-fidelity prototype to grow and harvest Spirulina, and it took 21 days. The test simulated real-life daily use. The device was placed in a domestic environment, away from direct sunlight, to avoid photosaturation. An attempt was made to keep the lighting and bubbling cycles constant throughout the test period. The same goes for temperature. Daily variations indicated the authenticity of the test and reflected what could happen in a typical use-case scenario. The tank was filled with $4 \mathrm{~L}$ of drinking water, including the alive Spirulina inoculum. The parameters of illumination and bubbling time, temperature, $\mathrm{pH}$, evaporation, culture density, and amount of Spirulina harvested were checked daily. Data are available in Table 4. On day 11, the culture density was optimal, and Spirulina was ready to be harvested. A culture is thick when the color becomes a dark green. With that density, even the LED light inside the tank was difficult to see from the outside. From day 12 and for the following ten days, about $5 \mathrm{~g}$ of fresh biomass were collected every day. This test showed the device could produce a modest quantity of fresh Spirulina daily, as expected. The culture had no external contamination, and so it should be safe for food use. The water evaporation was minimal; nevertheless, with more prolonged use of the device, it may be necessary to add a little water from time to time. A higher temperature could have ensured greater yields. However, this prototype did not have a heater. The test also showed the device had no relevant technical problems.

A second test addressed usability issues and collected qualitative perceptive and cognitive data. Five attendees interacted with the device: they were then asked a few open-ended questions; the moderator also took notes on user behavior and non-verbal cues. Most of the interviewees believed the product's design matched its purpose. However, behavioral observation showed that it would be advisable to provide simple instructions to tell users how to grow, take care, and collect Spirulina properly since this device may have a hidden affordance. The test confirmed that the prototyping insights worked out as expected providing useful information on how to improve user experience. 
Table 4. The Algae Grower: daily parameters collected during the growing and harvesting test.

\begin{tabular}{|c|c|c|c|c|c|c|c|}
\hline Day & Illumination & Bubbling & Temperature & $\mathrm{pH}$ & Density & Evaporation & Harvest \\
\hline 1 & $1 \mathrm{~h} 20 \min ^{1}$ & $4 \mathrm{~h}$ & $29.8^{\circ} \mathrm{C}$ & 10.4 & $33 \mathrm{~mm}$ & $1 \mathrm{~mm}$ & - \\
\hline 2 & $1 \mathrm{~h} 20 \mathrm{~min}$ & $4 \mathrm{~h}$ & $28.7^{\circ} \mathrm{C}$ & 10.5 & $33 \mathrm{~mm}$ & $1 \mathrm{~mm}$ & - \\
\hline 3 & $1 \mathrm{~h} 20 \mathrm{~min}$ & $4 \mathrm{~h}$ & $27.5^{\circ} \mathrm{C}$ & 10.4 & $32 \mathrm{~mm}$ & $1 \mathrm{~mm}$ & - \\
\hline 4 & $1 \mathrm{~h} 20 \mathrm{~min}$ & $4 \mathrm{~h}$ & $29.7^{\circ} \mathrm{C}$ & 10.2 & $29 \mathrm{~mm}$ & $1 \mathrm{~mm}$ & - \\
\hline 5 & $1 \mathrm{~h} 20 \mathrm{~min}$ & $4 \mathrm{~h}$ & $27.6^{\circ} \mathrm{C}$ & 10.6 & $27 \mathrm{~mm}$ & $1 \mathrm{~mm}$ & - \\
\hline 6 & $6 \mathrm{~h}$ & $6 \mathrm{~h}$ & $37.3^{\circ} \mathrm{C}$ & 10.4 & $25 \mathrm{~mm}$ & $2 \mathrm{~mm}$ & - \\
\hline 7 & $6 \mathrm{~h}$ & $6 \mathrm{~h}$ & $37.5^{\circ} \mathrm{C}$ & 10.8 & $18 \mathrm{~mm}$ & $1 \mathrm{~mm}$ & - \\
\hline 8 & $6 h$ & $6 \mathrm{~h}$ & $37.4^{\circ} \mathrm{C}$ & 10.8 & $13 \mathrm{~mm}$ & $2 \mathrm{~mm}$ & - \\
\hline 9 & $6 \mathrm{~h}$ & $6 \mathrm{~h}$ & $37.6^{\circ} \mathrm{C}$ & 11.0 & $10 \mathrm{~mm}$ & $2 \mathrm{~mm}$ & - \\
\hline 10 & $4 \mathrm{~h}$ & $4 \mathrm{~h}$ & $37.2^{\circ} \mathrm{C}$ & 11.1 & $9 \mathrm{~mm}$ & $1 \mathrm{~mm}$ & - \\
\hline 11 & $4 \mathrm{~h}$ & $4 \mathrm{~h}$ & $37.1^{\circ} \mathrm{C}$ & 11.3 & $8 \mathrm{~mm}$ & $1 \mathrm{~mm}$ & - \\
\hline 12 & $4 \mathrm{~h}$ & $4 \mathrm{~h}$ & $37.3^{\circ} \mathrm{C}$ & 11.1 & $4 \mathrm{~mm}$ & $2 \mathrm{~mm}$ & $5.2 \mathrm{~g}$ \\
\hline 13 & $4 \mathrm{~h}$ & $4 \mathrm{~h}$ & $37.4{ }^{\circ} \mathrm{C}$ & 11.2 & $3 \mathrm{~mm}$ & $1 \mathrm{~mm}$ & $5.3 \mathrm{~g}$ \\
\hline 14 & $4 \mathrm{~h}$ & $4 \mathrm{~h}$ & $37.2^{\circ} \mathrm{C}$ & 10.9 & $4 \mathrm{~mm}$ & $2 \mathrm{~mm}$ & $5.0 \mathrm{~g}$ \\
\hline 15 & $6 \mathrm{~h}$ & $6 \mathrm{~h}$ & $37.8^{\circ} \mathrm{C}$ & 10.8 & $4 \mathrm{~mm}$ & $1 \mathrm{~mm}$ & $5.7 \mathrm{~g}$ \\
\hline 16 & $6 \mathrm{~h}$ & $6 \mathrm{~h}$ & $37.9^{\circ} \mathrm{C}$ & 11.1 & $5 \mathrm{~mm}$ & $1 \mathrm{~mm}$ & $5.3 \mathrm{~g}$ \\
\hline 17 & $6 \mathrm{~h}$ & $6 \mathrm{~h}$ & $37.7^{\circ} \mathrm{C}$ & 11.2 & $4 \mathrm{~mm}$ & $2 \mathrm{~mm}$ & $5.5 \mathrm{~g}$ \\
\hline 18 & $6 \mathrm{~h}$ & $6 \mathrm{~h}$ & $37.5^{\circ} \mathrm{C}$ & 11.1 & $5 \mathrm{~mm}$ & $1 \mathrm{~mm}$ & $5.2 \mathrm{~g}$ \\
\hline 19 & $6 \mathrm{~h}$ & $6 \mathrm{~h}$ & $37.8^{\circ} \mathrm{C}$ & 11.1 & $4 \mathrm{~mm}$ & $2 \mathrm{~mm}$ & $5.2 \mathrm{~g}$ \\
\hline 20 & $6 \mathrm{~h}$ & $6 \mathrm{~h}$ & $37.7^{\circ} \mathrm{C}$ & 11.1 & $5 \mathrm{~mm}$ & $1 \mathrm{~mm}$ & $5.0 \mathrm{~g}$ \\
\hline 21 & $6 \mathrm{~h}$ & $6 \mathrm{~h}$ & $37.5^{\circ} \mathrm{C}$ & 11.1 & $5 \mathrm{~mm}$ & $1 \mathrm{~mm}$ & $5.7 \mathrm{~g}$ \\
\hline
\end{tabular}

${ }^{1}$ Prolonged use of the device caused the transformer circuit board to overheat. Therefore, the lighting time in the first five days is notably less, as well as the temperature and the consequent growth rate. On day 6, the $24 \mathrm{~W}$ transformer was replaced with a $60 \mathrm{~W}$ transformer to carry more power and prevent overheating.

\subsection{The Algae Station}

Another output of the practice-based research is the Algae Station, a modular installation for fresh Spirulina production and the distribution of microalgae-based food products. The apparatus can be located in indoor and outdoor public spaces, providing real-time information about the quantity of Spirulina produced and carbon dioxide subtracted through photosynthetic activity. The Algae Station aims to improve the experience of growing, harvesting, and distributing Spirulina in the city while attempting to optimize shapes, spaces, and various functions. In its basic combination, it is the size of a vending machine. Three main modules can be arranged in countless configurations:

1. Dry Spirulina vending machine: it stores and distributes dry Spirulina-based food products processed by third parties (restaurants, bakeries, and other local businesses). Users can purchase products through a touchscreen. When not in use, the monitor shows educational videos in the loop, illustrating the benefits of microalgae and the positive effects of urban production. This module can operate independently and is the minimum configuration of the Algae Station.

2. Fresh Spirulina vending machine: it distributes fresh Spirulina. The module works alongside one or more photobioreactors (module 3). The external appearance is very similar to that of module 1. Internally, an automatic pump system separates the algal biomass from the water, rich in nutrients, through one or more filters. Users can fill their bottles with fresh Spirulina.

3. Photobioreactor: it guarantees biomass production. The module consists of a large, high-quality transparent tubular tank. A low consumption lighting system, which provides light and heats the culture, is installed inside each tube. Multiple photobioreactors can be placed side by side to produce more biomass. The tanks are connected to module 2, which also contains the electronic components needed for their operation. Figure 9 shows the Algae Station configuration with a fresh Spirulina vending machine and a photobioreactor module. 


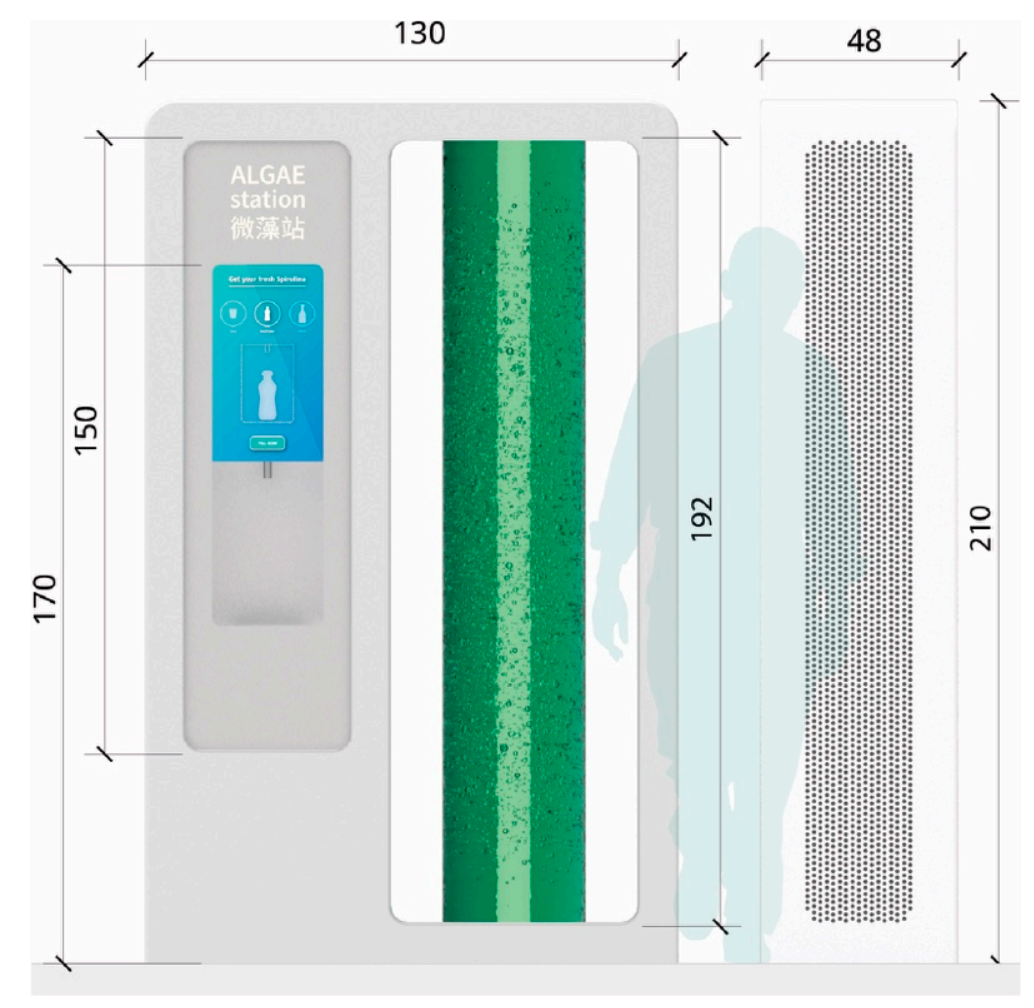

Figure 9. Orthographic front and side views of a configuration of the Algae Station, with one fresh Spirulina vending machine and one photobioreactor module. Quotes in $\mathrm{cm}$.

A 1:10 scale non-functional model of the Algae Station was realized to better understand the parts' proportions, the materials, and the overall potential look. Nevertheless, the Algae Station is still in a preliminary concept phase. Some possible microalgae production scenarios were proposed using the Algae Station in different configurations, for instance, on a university campus. This scenario results from the elaboration of a few solutions-or combinations between them-presented by the participants in the workshop. In a university, the management handles installation and maintenance fees. External (or internal) laboratories provide consultancy, together with the algae inoculum and the certified nutrients for food use. The biomass produced is sent to the canteen daily, which prepare recipes with high nutritional values for students and employees. Any excess biomass could be sold to other interested stakeholders (e.g., nearby food companies, residential compounds). Individuals can also join an association of volunteers with the responsibility of monitoring the culture and collecting fresh Spirulina. They can receive academic credit as an incentive. The system map in Figure 10 shows the different actors and their reciprocal links in this prospective scenario.

This installation has evident limitations but great potential. Further tests will indeed be necessary to assess its functions and usability. These tests could also be done with inexpensive and straightforward mockups, and their results will provide indispensable indications in the future design and engineering phases. Additionally, the service model of the Algae Station needs validation with regards to its medium-long term self-sustainability. As emerged from a previous study by Griffa and Vissio [52], the system could be economically viable if the labor expense is part of community activities or if it is shared with other activities, such as building management (as in the case of an installation in a residential compound). A constant, albeit modest, income could be the driving force for inducing citizens to urban food self-production and the creation of cohesive communities sensitive to environmental issues. 


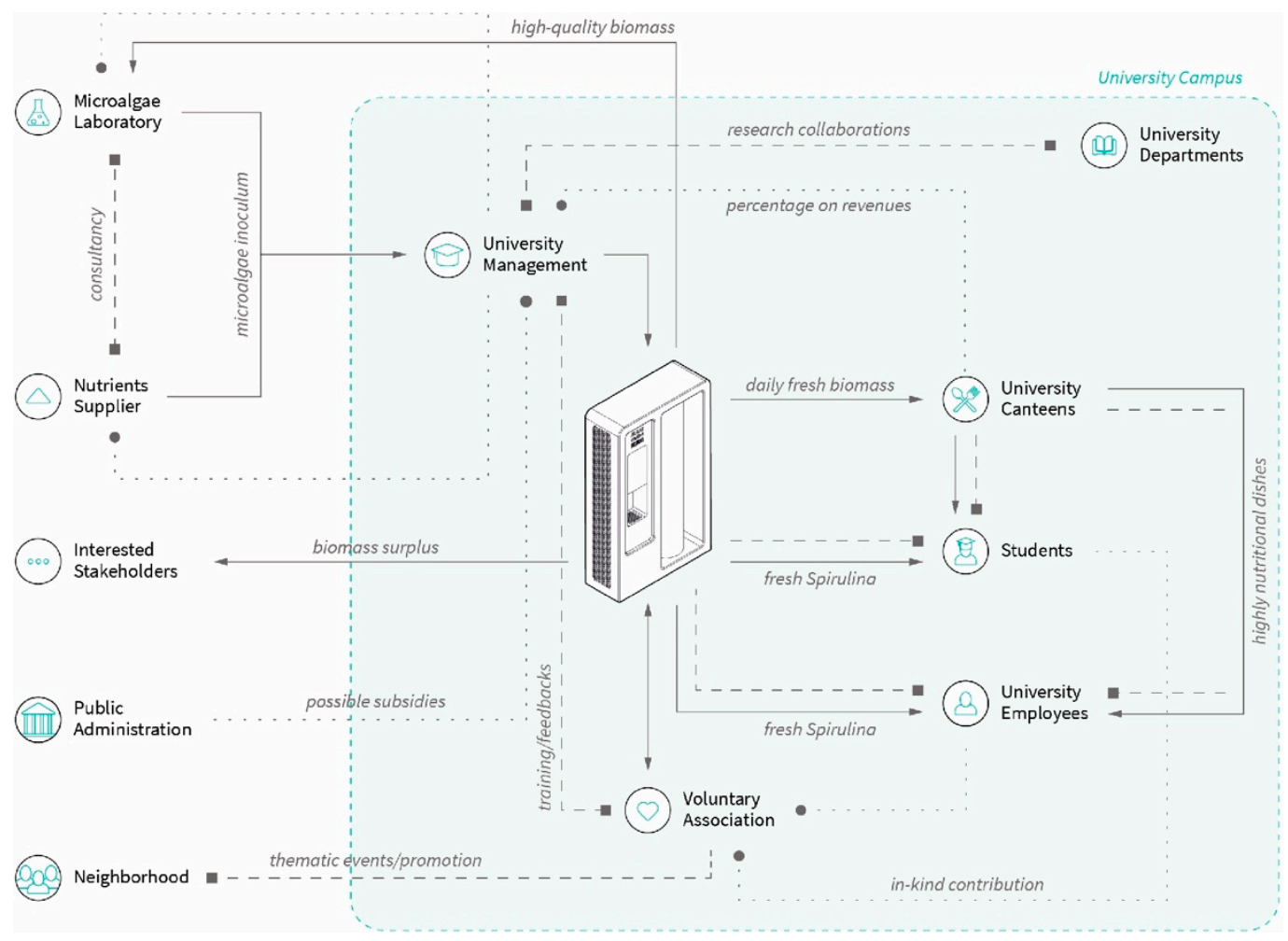

Figure 10. Fresh Spirulina production in a university campus: system map.

Values behind the Physical Product

The value of the Algae Station does not only lie in the product itself. The Algae Station is a change maker: it assumes an important role that goes far beyond the tangible. This modular device can be placed just about everywhere. As a result of this flexibility, it is possible to create aggregative hubs from scratch - even in the poorest and most degraded areas-favoring communities' creation and acting as a local landmark. Being actively involved in the Algae Station management is a vocational job opportunity or a volunteering activity for locals: the activities can help build social relationships among neighbors. A positive attitude to collaboration sets the foundation for successful bottomup initiatives. Well-educated people assume more responsible behaviors because they are also aware of their significant role in civil society. The awareness of producing and eating healthy, nutritious, and locally-sourced food also brings gains in environmental sustainability, with cascading benefits both in the short and medium-long term for people involved in the system, as well as those outside the system.

\subsection{Theoretical Framework}

A theoretical framework is a conceptual structure that supports a particular research subject. It matters in research because we can more easily imagine and understand the study in its broader context, identifying fundamental notions and conceptual relations between them. The theoretical framework for the realization of microalgae-based design projects is presented in Figure 11. The framework underlines the main challenges posed by designing innovative products, services, systems, and experiences involving microalgae: researchers and professionals coming from different fields can use it as a reference for developing new projects.

A fundamental aspect is sustainability. Innovative projects must respond to particular social, economic, and environmental needs to be impactful, and the use of microalgae is only one of the many possible solutions for achieving sustainability. Approaches to the project would be better if multidisciplinary. Working with experts with assorted backgrounds 
requires a longer time, but it guarantees superior results because all the different facets of the problem are pondered. A great project has solid foundations: therefore, designers must consider its technological, political-economic, and socio-cultural implications. It is necessary to use technology correctly, but this can never be the only solution. Undoubtedly, the wise use of the available technology could increase, for instance, efficiency, automation, and security. From an economic point of view, the project should bring value, and its business model should be sustainable over time. Local policies should also be respected: this is particularly important for services that operate within a sharing economy model. Finally, it is necessary to act on the socio-cultural sphere to inspire citizens and users to change their behaviors, make them interested on the project's benefits, and educate them on a more environmental-friendly lifestyle. The latter is a challenging but indispensable task to eradicate well-established production and consumption paradigms. Following these indications, the possible design projects are virtually unlimited and can operate on different scales: micro-macro, private-public, product-service. Design decisions will be made to select and develop the solutions that are considered most valid, based on the project brief (e.g., Algae Grower and Algae Station). This framework can be adapted to as many different design contexts.

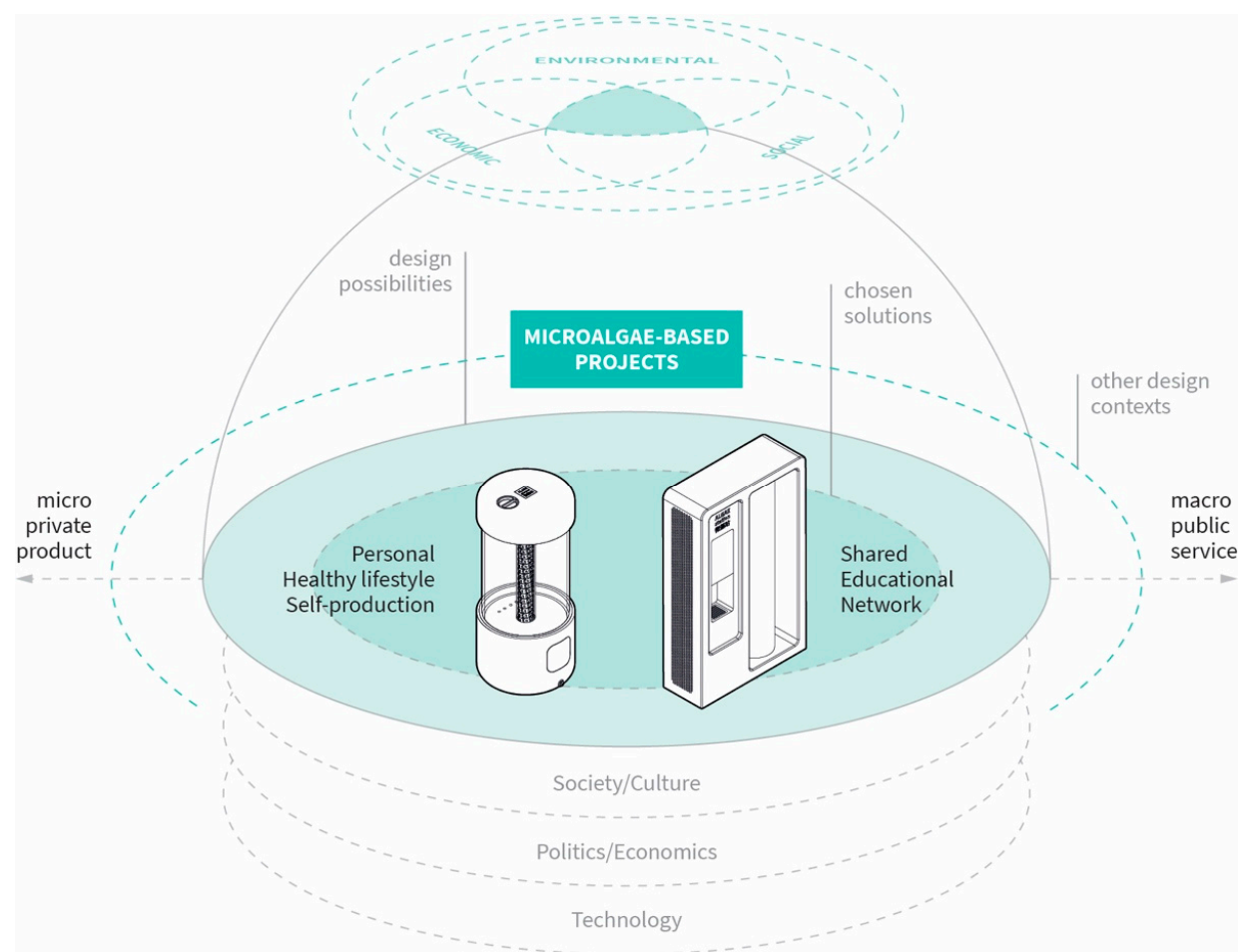

Figure 11. The theoretical framework for realizing microalgae-based design projects including sustainability, socio-cultural, economic, and technological implications.

\section{Discussion}

Designing the Algae Grower and the Algae Station has been challenging and educational. The Algae Grower is a futuristic device for the cultivation of microalgae at home. However, such a practice is not widespread nowadays, and the utility of this product may not be immediately recognized. The domestic production of natural and sustainable foods is not new, though, and the present and future trends bode well. For example, in the 1990s, bread-baking machines were widely used by the American and European middle class. Thirty years later, bread machines are practically non-existent, but more and more health-conscious people-especially young consumers-are rediscovering the advantages of these devices, desiring to know what goes into their food, and to produce gluten-free 
bread, pizza, and other delicious recipes [53]. The same goes for yogurt machines enabling concerned consumers to produce low-fat yogurt with no added sugar. Kitchen counter devices such as bread-baking machines, yogurt machines, juice extractors, but even microwaves and toasters were unthinkable in the past. The current needs of individuals and societies lead us to imagine new devices, new functions, new rituals of use, and decentralized models to produce healthy and sustainable food. The Algae Grower, hence, fits into this context and operates in a particular niche market.

The practice-based research demonstrated it is possible to self-produce a Spirulinaharvesting device. In the effort to guarantee a more widespread adoption of the product, the instructions for the reproduction of the Algae Grower have been made available online in open source. Open design is an emerging phenomenon intended as the "free revealing of information on a new design with the intention of collaborative development of a single design or a limited number of related designs for market or non-market exploitation" [54] (p. 383). The Algae Grower could be independently reproduced by others, who could use available resources, including receiving support from their local Fab Labs. Users would also have the option to improve some components and add (or remove) features based on their needs, thus filling some technical limitations of the current prototype.

Regarding the Algae Station, it is an eye-catching modular installation with a strong identity. At present, it is still a concept: the intent in the near future is to engineer the product in all its parts. Nonetheless, the Algae Station's production and installation costs may be considerable, given the use of various high-performing technical elements, i.e., glass pipes, air and carbon dioxide pumping systems, lighting apparatus, biomass distribution mechanism. A redesigned, cheaper, and more rudimentary but less appealing device can be more easily replicated and adapted to guarantee a higher degree of diffusion, especially in less wealthy areas. Vending machines can be highly profitable if the business is adequately structured and positioned in the right places. However, without a pilot project, it is impossible to verify how-and if - the Algae Station can be successful. The Algae Station's indirect benefits on job creation and health improvement are also difficult to quantify with scientific rigor.

\section{Conclusions}

Methodological practice-based research has proved to be a useful tool for advancing knowledge in such a particular area of study. This real-world experimentation got out of the walls of academia through a practical but still theoretically-valuable project, which attracted the interest of professionals from different fields of knowledge. The feedback obtained so far is encouraging. At the time of writing, more than 780 people consulted the instructions for the self-production of the Algae Grower, and the project gathered dozens of followers on Wikifactory, a social platform for collaborative product development made for opensource communities, designers, and product companies [47]. A Brazilian oceanographer researcher and a Japanese botanist and museum curator are currently replicating the Algae Grower $[55,56]$. Interestingly, both are not designers: this confirms that cross-disciplinary cooperation and collaborative processes with scientists are vital in promoting technical and humanistic research in this domain. Hopefully, the project will get greater involvement of the international maker community. A high level of public awareness is a step toward redefining resilient, sustainable food production and consumption patterns.

This research answers some questions, but at the same time, raises new issues. Sustainable design emerged more than a half-century ago and has developed and improved its theory and methods (e.g., LCA, triple bottom) as our society is transforming. However, food-strictly connected to natural resources and energy — is not an archetypal design topic. When talking about service-systems for food production, is it still appropriate to assess them with the aforementioned methods? More specifically, should the life cycle of the food-production devices be included in the life cycle assessment of food? To what extent, for instance, would the sustainability of microalgal production be recognized? These may 
be sociopolitical rather than design matters, and further innovation would highly rely on in-depth discourse.

This research comprehensively discussed microalgae production with a systematic design investigation from the perspective of current possible applications. Nevertheless, if looking at an even further future, radically different scenarios open up. For example, with rising sea levels and limited farming land, seafood may become the primary nutrition source for humans. How would microalgae be produced, processed, and distributed then? If human settlements expand into areas that were considered unlivable before (e.g., deserts, plateaus) and distributed renewable energy, water, and production systems become mainstream, how would they work? How would human lifestyles be shaped? These revolutionary scenarios will inspire new approaches to microalgal studies and substantially contribute to sustainable design research per se.

Author Contributions: M.V. is the corresponding author of this manuscript. He is the primary author of the manuscript. Conceptualization, M.V. and P.P.P.; methodology, M.V., P.P.P. and X.L.; validation, M.V. and Y.S.; formal analysis, M.V. and Y.S.; investigation, M.V.; resources, M.V., P.P.P., X.L. and F.Z.; writing—original draft preparation, M.V.; writing—review and editing, M.V., P.P.P., X.L., F.Z. and Y.S.; visualization, M.V.; supervision, M.V. and P.P.P. All authors have read and agreed to the published version of the manuscript.

Funding: This research received no external funding.

Institutional Review Board Statement: Not applicable.

Informed Consent Statement: Not applicable.

Data Availability Statement: Not applicable.

Acknowledgments: This work is largely extracted from Maurizio Vrenna's unpublished doctoral dissertation - Vrenna, M. Design and Microalgae. A Self-Produced System to Grow Spirulina for Food Use. Ph.D. Thesis, Politecnico di Torino, Turin, Italy, 2021. The research was carried out at Politecnico di Torino (Turin, Italy) and Tsinghua University (Beijing, China) with Pier Paolo Peruccio as an academic tutor and Liu Xin as a co-tutor. Zhong Fang and Sun Yuchi provided valuable theoretical insights and technical assistance.

Conflicts of Interest: The authors declare no conflict of interest.

\section{Appendix A}

Table A1. The most representative design experimentations involving microalgae since 2008 (data as of September 2019).

\begin{tabular}{|c|c|c|c|c|}
\hline & Project Name & Designer(s) & Place & Period \\
\hline 1 & Flood $\odot$ & Mathieu Lehanneur & Paris, France & May 2008 \\
\hline 2 & Symbiosis & Jelte van Abbema & Wageningen, The Netherlands & October 2009 \\
\hline 3 & Latro Lamp & Mike Thompson & Eindhoven, The Netherlands & June 2010 \\
\hline 4 & Algae-graphies & Lia Giraud & Paris, France & March 2011 \\
\hline 5 & Moss Table & Peralta, Driver, \& Bombelli & Cambridge, UK & October 2011 \\
\hline 6 & Algae Curtain & Loop.pH & Lille, France & October 2012 \\
\hline 7 & Eco-friendly Lamp & Pierre Calleja & Libourne, France & April 2013 \\
\hline 8 & Algaerium Bioprinter & Marin Sawa & London, UK & July 2013 \\
\hline 9 & Dino Pet & Yonder Biology & San Diego, CA, USA & August 2013 \\
\hline 10 & Algaemy & Blond \& Bieber & Berlin, Germany & $2014,-$ \\
\hline 11 & Living Things & Douenias \& Frier & Pittsburgh, PA, USA & May 2015 \\
\hline 12 & Farma & William Patrick & Cambridge, MA, USA & December 2015 \\
\hline 13 & Timelapse Ink & Living Ink & Fort Collins, CO, USA & April 2016 \\
\hline 14 & CMYKA & Leon Brown & Edinburgh, UK & December 2016 \\
\hline 15 & Exhale Bionic Chandelier & Julian Melchiorri & London, UK & September 2017 \\
\hline 16 & 3D Bakery & Klarenbeek \& Dros & Zaandam, The Netherlands & November 2017 \\
\hline 17 & Spirugrow & Bentur & Pordenone, Italy & January 2018 \\
\hline 18 & Carbon Eaters & PUMA \& MIT Design Lab & Milan, Italy & April 2018 \\
\hline 19 & Symbiont & Andriana Nassou & London, UK & July 2018 \\
\hline 20 & The Coral & Hyunseok An & Providence, Rhode Island & June 2019 \\
\hline
\end{tabular}




\section{Appendix B}

Table A2. The elements used in the experiment. Physical, chemical, and biological parts.

\begin{tabular}{ccc}
\hline Element & Specifications & Model \\
\hline Transparent glass aquarium & $10 \mathrm{~L}, 295 \times 200 \times 215 \mathrm{~mm}$ & SUNSUN HRK-300 \\
\hline LED lamp & $\begin{array}{c}\text { Easy clip-on support, } \\
\text { movable mechanism }\end{array}$ & AMD-D2 $/ 4 \mathrm{~W}$ \\
\hline Air pump & $4 \mathrm{~W}, 2$ air outlets & SUNSUN CT-402 \\
\hline Air hose & $150 \mathrm{~mm}$ & - \\
\hline Bubble tube & Stainless steel, $300 \mathrm{~mm}$ & - \\
\hline Digital thermometer & $\begin{array}{c}\text { Battery-powered, } \\
\text { submersible probe }\end{array}$ & SUNSUN WDJ-004 \\
\hline Aquarium heater & $\begin{array}{c}25 \mathrm{~W}, \text { submersible, } \\
\text { range } 18-32{ }^{\circ} \mathrm{C}\end{array}$ & SUNSUN GB-25B \\
\hline Harvesting sieve & Circular shaped, $150 \mathrm{~mm}$ & - \\
\hline Beaker & $1 \mathrm{~L}$ & - \\
\hline Secchi stick & - & - \\
\hline pH meter & - & - \\
\hline Spirulina culture & $500 \mathrm{~mL}$ & - \\
\hline Culture nutrients & Modified formula f $/ 2$ & bags, $50 \mathrm{~mL}$ each \\
\hline Culture salts & & \\
\hline
\end{tabular}

\section{Appendix C}

Table A3. The list of the components used for the high-fidelity prototype of the Algae Grower.

\begin{tabular}{|c|c|c|c|}
\hline No. & Element & Specifications & Model \\
\hline 1 & Acrylic Tube & $\begin{array}{c}\text { Transparent, external } \varnothing 160 \\
\text { mm, length } 250 \mathrm{~mm}, \\
\text { thickness } 5 \mathrm{~mm}\end{array}$ & - \\
\hline 1 & Acrylic Tube & $\begin{array}{l}\text { Transparent, external } \varnothing \\
35 \mathrm{~mm} \text {, } \\
\text { length } 270 \mathrm{~mm} \text {, thickness } \\
2 \mathrm{~mm}\end{array}$ & - \\
\hline 1 & PVC Tube & $\begin{array}{l}\text { Matte white, external } \varnothing \\
25 \mathrm{~mm} \text {, length } 280 \mathrm{~mm} \text {, } \\
\text { thickness } 1.5 \mathrm{~mm}\end{array}$ & - \\
\hline 1 & LED Strip & $\begin{array}{l}\text { Warm white, adhesive, } \\
\text { length } \sim 2 \mathrm{~m}, 18 \mathrm{~W} / \mathrm{m}\end{array}$ & \\
\hline 2 & Water Pumps & $6 \mathrm{~W}$, peristaltic, medical grade & KAMOER NK- PDCS10 \\
\hline 2 & Aeration Pumps & Ultra-quiet, $1.5 \mathrm{~W}$ & SUNSUN QB-104B \\
\hline 3 & Check Valves & One-way & - \\
\hline 4 & Pipe Connectors & $\begin{array}{c}\text { Quick-screw, } \\
\text { straight-through and T-type }\end{array}$ & - \\
\hline 1 & Magnetic Buckle & $48-58 \mathrm{~mm}$ stroke & QUFEN 156484486389635 \\
\hline 2 & Acrylic Rods & $\begin{array}{c}\text { Transparent, } \\
\varnothing 5 \mathrm{~mm} \text {, length } 94 \mathrm{~mm}\end{array}$ & - \\
\hline
\end{tabular}


Table A3. Cont.

\begin{tabular}{cccc}
\hline No. & Element & Specifications & Model \\
\hline 4 & Electric Boards & - & - \\
\hline 3 & Button Switchers & $\begin{array}{c}\text { Metal, self-locking, } \\
\text { waterproof }\end{array}$ & $\begin{array}{c}\text { RONGYUHUAFU } \\
\text { 2016010305922942 }\end{array}$ \\
\hline 1 & DC Power Plug & Socket connector & TELESKY DC-099 \\
\hline 3 & Magnets & $\begin{array}{c}\text { High-strength neodymium, } \\
\text { with M5 screw hole }\end{array}$ & - \\
\hline 1 & Filter Cloth & $\begin{array}{c}\text { Nylon mesh, 38/106 } \mu \mathrm{m} \\
\text { mesh }\end{array}$ & - \\
\hline 1 & Gasket & Silicone, thickness 2 mm & - \\
\hline- & Screws and Bolts & M5 & - \\
\hline- & Waterlines / Airlines & Soft plastic, $\varnothing 5 \mathrm{~mm}$ & - \\
\hline
\end{tabular}

\section{References}

1. Oxfam. The Hunger Virus: How COVID-19 Is Fuelling Hunger in a Hungry World. Available online: https: / oxfamilibrary. openrepository.com/bitstream/handle/10546/621023/mb-the-hunger-virus-090720-en.pdf (accessed on 14 January 2021).

2. Cui, K.; Shoemaker, S.P. A Look at Food Security in China. NPJ Sci. Food 2018, 2, 1-2. [CrossRef] [PubMed]

3. UN. Transforming Our World: The 2030 Agenda for Sustainable Development. Available online: https://www.un.org/ga/ search/view_doc.asp?symbol=A/RES/70/1\&Lang=E (accessed on 14 January 2021).

4. Khush, G.S. Green Revolution: The Way Forward. Nat. Rev. Genet. 2001, 2, 815-822. [CrossRef]

5. Tilman, D. The Greening of the Green Revolution. Nature 1998, 396, 211-212. [CrossRef]

6. Lynch, J.P. Roots of the Second Green Revolution. Aust. J. Bot. 2007, 55, 493-512. [CrossRef]

7. Foley, J. A Five-Step Plan to Feed the World. Available online: https://www.nationalgeographic.com/foodfeatures/feeding-9billion/ (accessed on 16 January 2021).

8. Hendrich, S. Novel foods. In Encyclopedia of Food and Health; Caballero, B., Finglas, P.M., Toldrá, F., Eds.; Academic Press: Cambridge, MA, USA, 2016; ISBN 9780-1238-4947-2.

9. Meyerding, S.G.H.; Kürzdörfer, A.; Gassler, B. Consumer Preferences for Superfood Ingredients-The Case of Bread in Germany. Sustainability 2018, 10, 4667. [CrossRef]

10. Estell, M.; Hughes, J.; Grafenauer, S. Plant Protein and Plant-Based Meat Alternatives: Consumer and Nutrition Professional Attitudes and Perceptions. Sustainability 2021, 13, 1478. [CrossRef]

11. Soylent. Available online: https:/ / soylent.com (accessed on 21 February 2021).

12. Fogliano, V. Food Design: Quality Matters! Wageningen University: Wageningen, The Netherlands, 2014; ISBN 9789-4617-3977-3.

13. Alvaro, C. Lab-Grown Meat and Veganism: A Virtue-Oriented Perspective. J. Agric. Environ. Ethics 2019, 32, 127-141. [CrossRef]

14. CBI. Product Factsheet-Superfoods in Europe. Available online: https://fdocuments.us/document/product-factsheetsuperfoods-in-europe (accessed on 19 January 2021).

15. Schiemer, C.; Halloran, A.; Jespersen, K.; Kaukua, P. Marketing insects: Superfood or solution-food. In Edible Insects in Sustainable Food Systems; Halloran, A., Flore, R., Vantomme, P., Roos, N., Eds.; Springer Nature: Amsterdam, The Netherlands, 2018; ISBN 978-3-319-74011-9.

16. Tomaselli, L. The microalgal cell. In Handbook of Microalgal Culture: Biotechnology and Applied Phycology; Richmond, A., Ed.; Blackwell Science: Oxford, UK, 2004; ISBN 9780632059539.

17. Ciferri, O. Spirulina, the Edible Microorganism. Microbiol. Rev. 1983, 47, 551-578. [CrossRef]

18. Henrikson, R. Spirulina: World Food, How This Micro Algae Can Transform Your Health and Our Planet; Rorore Enterprises: Maui, HI, USA, 2010; ISBN 1453766987.

19. Wikfors, H.G.; Ohno, M. Impact of Algal Research in Aquaculture. J. Phycol. 2001, 37, 968-974. [CrossRef]

20. Jung, F.; Krüger-Genge, A.; Waldeck, P.; Küpper, J.-H. Spirulina Platensis, a Super Food? J. Cell. Biotechnol. 2019, 5, 43-54. [CrossRef]

21. Sánchez, M.; Bernal-Castillo, J.; Rozo, C.; Rodríguez, I. Spirulina (Arthrospira): An Edible Microorganism. A Review. Univ. Sci. 2003, 8, 7-24. [CrossRef]

22. Henrikson, R. Algae Microfarms; Ronore Enterprises: Richmond, VA, USA, 2013; ISBN 148396826X.

23. Ponce López, E. Superalimento Para un Mundo en Crisis: Spirulina a Bajo Costo. Idesia 2013, 31, 135-139. [CrossRef]

24. FAO. The State of Food and Agriculture. 1947. Available online: http://www.fao.org/3/ap635e/ap635e.pdf (accessed on 10 January 2021).

25. Belasco, W. Algae Burgers for a Hungry World? The Rise and Fall of Chlorella Cuisine. Technol. Cult. 1997, 38, 608-634. [CrossRef] 
26. Paddock, M.B. Microalgae Wastewater Treatment: A Brief History. Preprints 2019. [CrossRef]

27. Sasson, A. Microalgal biotechnologies: Recent developments and prospects for developing countries. In Proceedings of the Asia-Pacific Marine Biotechnology Conference and Asia-Pacific Conference on Algal Biotechnology, Phuket, Thailand, 7-10 May 1997; pp. 11-31.

28. Abdulqader, G.; Barsanti, L.; Tredici, M.R. Harvest of Arthrospira Platensis from Lake Kossorom (Chad) and its Household Usage Among the Kanembu. J. Appl. Phycol. 2000, 12, 493-498. [CrossRef]

29. Piccolo, A. Spirulina-A Livelihood and a Business Venture. Available online: http://www.fao.org/3/a-az386e.pdf (accessed on 10 January 2021).

30. Habib, M.A.B.; Parvin, M.; Huntington, T.C.; Hasan, M.R. A Review on Culture, Production and Use of Spirulina as Food for Humans and Feeds for Domestic Animals and Fish. Available online: http:/ /www.fao.org/3/i0424e/i0424e00.pdf (accessed on 20 February 2021).

31. Bobescu, E.; Bălan, A.; Moga, M.A.; Teodorescu, A.; Mitrică, M.; Dima, L. Are There Any Beneficial Effects of Spirulina Supplementation for Metabolic Syndrome Components in Postmenopausal Women? Mar. Drugs 2020, 18, 651. [CrossRef] [PubMed]

32. Al-Dhabi, N.A. Heavy Metal Analysis in Commercial Spirulina Products for Human Consumption. Saudi J. Biol. Sci. 2013, 20, 383-388. [CrossRef]

33. Myers, W. Bio Design: Nature + Science + Creativity; MoMA: New York, NY, USA, 2018; ISBN 1633450716.

34. Lee, C.; Lee, H.; Kim, O.B. Biocement Fabrication and Design Application for a Sustainable Urban Area. Sustainability 2018, 10, 4079. [CrossRef]

35. Correia Carreira, S.; Begum, R.; Perriman, A.W. 3D Bioprinting: The Emergence of Programmable Biodesign. Adv. Healthc. Mater. 2019, 9, 1900554. [CrossRef]

36. Vallas, T.; Courard, L. Using Nature in Architecture: Building a Living House with Mycelium and Trees. Front. Archit. Res. 2017, 6, 318-328. [CrossRef]

37. SPACE10. Future Food Today; Frame: Amsterdam, The Netherlands, 2019; ISBN 978-9492311405.

38. Twilley, N. Algae Caviar, Anyone? What We'll Eat on the Journey to Mars. Available online: https://www.wired.com/story/ space-food-what-will-keep-us-human/ (accessed on 18 January 2021).

39. Muratovski, G. Research for Designers: A Guide to Methods and Practice; SAGE: London, UK, 2016; ISBN 1446275140.

40. Candy, L. Practice-Based Research: A Guide. Available online: https://www.creativityandcognition.com/resources/PBR\%20 Guide-1.1-2006.pdf (accessed on 10 January 2021).

41. Peruccio, P.P.; Vrenna, M. Design and Microalgae. Sustainable Systems for Cities. Agathón 2019, 2, 218-227. [CrossRef]

42. Yin, R.K.; Davis, D. Adding New Dimensions to Case Study Evaluations: The Case of Evaluating Comprehensive Reforms. New Dir. Eval. 2007, 113, 75-93. [CrossRef]

43. Singh, R.N.; Sharma, S. Development of Suitable Photobioreactor for Algae Production-A Review. Renew. Sust. Energ. Rev. 2012, 16, 2347-2353. [CrossRef]

44. Moore, M. China Now Eats Twice as Much Meat as the United States. Available online: https://www.telegraph.co.uk/news/ worldnews/asia/china/9605048/China-now-eats-twice-as-much-meat-as-the-United-States.html (accessed on 30 December 2020).

45. Emili, S. Designing Product-Service Systems Applied to Distributed Renewable Energy in Low-Income and Developing Contexts: A Strategic Design Toolkit. Ph.D. Thesis, Brunel University London, London, UK, 2017.

46. Ciribini, G. Tecnologia e Progetto: Argomenti di Cultura Tecnologica della Progettazione; Celid: Turin, Italy, 1984 ; ISBN 8876610804.

47. Vrenna, M. Algae Grower. Available online: https://projects.fablabs.io/@mauriziovrenna/algae-grower (accessed on 6 January 2021).

48. Gnecchi, N. Q\&A with Maurizio Vrenna, Creator of the Algae Grower. Available online: https://wikifactory.com/+wikifactory/ stories / qa-with-maurizio-vrenna-creator-of-the-algae-grower (accessed on 7 January 2021).

49. Katsikopoulou, M. Algae Grower Home Device Can Satisfy Average Adult's Daily Nutritional Needs. Available online: https: / / www.designboom.com/design/algae-grower-home-device-average-adult-daily-nutritional-needs-07-13-2020/ (accessed on 7 January 2021).

50. Tabi Labo. For Stylish Interiors! "Spirulina Culture Kit” That You Can Do at Home. Available online: https://tabi-labo.com/29 6358/wt-algae-grower (accessed on 7 January 2021).

51. Mennen, R. Innovation of the Day. Algae Grower. Available online: https://info.trendwatching.com/innovation-of-the-day-thealgae-grower-simplifies-the-process-of-growing-spirulina-at-home (accessed on 7 January 2021).

52. Griffa, C.; Vissio, A. WaterLilly: Story of an Architectural Photobioreactor. Available online: https://drive.google.com/file/d/ 1VxFkWDO5fkZywy4yXEuUUz-_W1tfs3Vh/view (accessed on 3 January 2021).

53. Bautista, T. What Ever Happened to the Bread Machine? Available online: https://www.tastecooking.com/ever-happenedbread-machine/ (accessed on 30 January 2021).

54. Raasch, C.; Herstatt, C.; Balka, K. On the Open Design of Tangible Goods. R. D. Manag. 2009, 39, 382-393. [CrossRef]

55. Castelar, B. (Università degli Studi di Torino, Turin, Italy). Personal communication, 2020.

56. Tuji, A. (National Museum of Nature and Science, Amakubo, Japan). Personal communication, 2020. 